1 Heightened virulence of Yersinia is associated with decreased function of the

\title{
2 YopJ protein
}

4 Chris A. Mares ${ }^{\mathrm{a}^{*} \#}$, Fernando P. Lugo ${ }^{\mathrm{a}}$, Mohammad Albataineh ${ }^{\mathrm{a}}$, Beth A. Goins ${ }^{\mathrm{b}}$, Irene

5 G. Newton ${ }^{\text {c }}$, Ralph R. Isberg, ${ }^{\text {d,e\# }}$, and Molly A. Bergman ${ }^{\text {a }}$

6

7 a Departments of Microbiology \& Immunology, The University of Texas Health Science

8 Center at San Antonio

9 bepartment of Radiology, The University of Texas Health Science Center at San

10 Antonio

$11{ }^{\mathrm{C} D e p a r t m e n t}$ of Biology, Indiana University

12 dDepartment of Molecular Biology \& Microbiology, Tufts University School of Medicine

$13{ }^{\mathrm{e} H o w a r d}$ Hughes Medical Institute

14

$15{ }^{*}$ current address: Department of Life Sciences, Texas A\&M University-San Antonio, San

16 Antonio, Texas, United States of America

$17 \quad$ "Corresponding authors

18 Ralph.Isberg@Tufts.edu

19 Chris.Mares@tamusa.edu

20 keywords: T3SS, effector, YopJ, YopP, Yersinia, positive selection, Darwinian,

21 cytotoxicity, macrophage, avirulence 


\section{Abstract}

27 Despite the maintenance of YopP/J alleles throughout the human-pathogenic Yersinia 28 lineage, the benefit of YopP/J-induced phagocyte death for Yersinia pathogenesis in 29 animals is not obvious. To determine how sequence divergence of $\mathrm{YopP} / \mathrm{J}$ has 30 impacted Yersinia virulence, we examined protein polymorphisms in this Type III

31 secreted effector protein across 17 Yersinia species, and tested the consequences of 32 polymorphism in a murine model of sub-acute systemic yersiniosis. Our evolutionary 33 analysis revealed that codon 177 has been subjected to positive selection - the $Y$.

34 enterocolitica residue had been altered from a leucine to a phenylalanine in nearly all $Y$.

35 pseudotuberculosis and $Y$. pestis strains examined. Despite being a minor change, as

36 both leucine and phenylalanine have hydrophobic side chains, reversion of YopJ ${ }^{F 177}$ to

37 the ancestral YopJ ${ }^{L 177}$ variant yielded a $Y$. pseudotuberculosis strain with enhanced

38 cytotoxicity towards macrophages, consistent with previous findings. Surprisingly,

39 expression of $\mathrm{YopJ}^{\mathrm{F} 177 \mathrm{~L}}$ in the mildly attenuated $k s g A^{-}$background rendered the strain

40 completely avirulent in mice. Consistent with this hypothesis that YopJ activity indirectly

41 relates to Yersinia pathogenesis in vivo, $k s g A^{-}$strains lacking functional YopJ failed to

42 kill macrophages but actually regained virulence in animals. Also, treatment with the

43 anti-apoptosis drug suramin prevented YopJ-mediated macrophage cytotoxicity and

44 enhanced Y. pseudotuberculosis virulence in vivo. Our results demonstrate that

45 Yersinia-induced cell death is detrimental for bacterial pathogenesis in this animal 
46 model of illness, and indicate that positive selection has driven YopJ/P and Yersinia

47 evolution towards diminished cytotoxicity and increased virulence, respectively.

48 Introduction

50 Bacterial pathogens induce host cell death by various mechanisms, and with

51 downstream consequences that seem counterintuitive (1). At face value, death of host

52 cells, particularly cells of the innate immune system, should cripple the host immune

53 response and allow pathogens to escape clearance. However, the opposite often

54 occurs - induction of host cell death can induce a host response that leads to pathogen

55 removal (1). Mechanisms underlying this outcome are incompletely understood, but

56 likely include removing niches for intracellular replication, or enhancing recruitment of

57 highly activated phagocytes that then ingest and degrade the offending bacteria. Both

58 host and bacterial factors are necessary for pathogen-induced host cell death -

59 caspase-1 being a notable player during macrophage pyroptosis (2) and required for

60 host protection against pyroptosis-inducing pathogens $(3,4)$. Thus, pathogen-triggered

61 cytotoxicity is a host defense strategy. But why do pathogens maintain the genes

62 encoding the pro-cytotoxicity factors in their genomes? The existence of such genes

63 throughout the bacterial kingdom suggests that host cell death plays an important role in

64 persistence of individual species.

65

66 Three species of mammalian-pathogenic Yersinia, the gastroenteritis-causing $Y$.

67 enterocolitica and Y. pseudotuberculosis and the plague-causing $Y$. pestis, have

68 maintained such a pro-cytotoxicity factor throughout their evolutionary history, in spite of 
69 significant genomic decay $(5,6)$. YopJ (so-called in $Y$. pestis and $Y$.

70 pseudotuberculosis, called YopP in Y. enterocolitica) is one of the 6-8 Type 3 secretion

71 system (T3SS) effector proteins (Yersinia outer proteins, Yops) injected by the bacteria

72 into host cells (7-9). YopJ has been described as having ubiquitin-like protein protease

73 (10), deubiquitinase $(11,12)$ and acyl transferase activity $(13,14)$, with the latter

74 requiring the host cell co-factor inositol hexaskisphosphate (15). In macrophages, YopJ

75 activity inhibits MAPK and NFאB signaling pathways, which in conjunction with TLR4

76 signaling results in host cell death (reviewed in (16)), and recent evidence demonstrates

77 that YopJ-induced phagocyte death occurs by a mechanism distinct from both apoptosis

78 and pyroptosis but linked to necrosis(17). Regardless of mechanism, the outcome is

79 clear - YopJ has profoundly negative effects on macrophage viability.

81 However, exactly what YopJ does for Yersinia in vivo is unclear. YopJ seems minimally

82 important for virulence, at least compared to most of the other Yops, as YopJ Y. pestis,

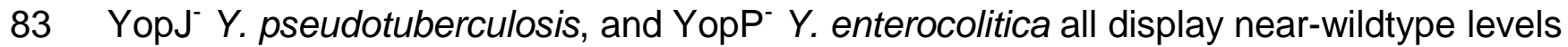

84 of virulence in various mouse models of acute illness (18-23). In contrast, there is

85 evidence indicating that YopJ activity may actually diminish Yersinia virulence, as

86 different isoforms of $\mathrm{YopP} / \mathrm{J}$ can alter the degree of macrophage death and mouse

87 illness following exposure to Yersinia. Y. pseudotuberculosis or Y. pestis expressing a

88 hypersecreted variant of YopP showed enhanced cytotoxicity towards cultured

89 macrophages but diminished virulence in mice $(24,25)$. Moreover, Y. pestis strain KIM

90 also encodes a hypercytotoxic YopJ variant, which when expressed in $Y$.

91 pseudotuberculosis induced more macrophage cell death due to enhanced IKK $\beta$ 
92 binding and thus reduced NFאB signaling; the impact of this variant upon $Y$.

93 pseudotuberculosis-caused illness in mice was not reported (26).

94

95 It is unknown if changes in YopP/J sequences occurred as a consequence of Darwinian

96 evolution, but given that host-pathogen interactions can exert strong natural selection

97 pressure upon both organisms (27), it seems likely that the YopJ-target protein

98 interactions have been guided by evolutionary pressure. Evidence of selection at the

99 codon level can be detected via phylogenetic analyses across multiple lineages to

100 detect patterns of protein polymorphisms relative to divergence $(28,29)$. The advantage

101 of this approach is that it can reveal loci affected by positive selection, even if the

102 selection pressure is obscure. Such analyses of bacterial pathogen effector proteins

103 have revealed signatures of molecular evolution, with individual codons showing

104 evidence of directional selection $(30,31)$.

106 To address the hypothesis that YopP/J has been subjected to directional selection, we

107 analyzed 17 sequences from multiple strains of each human-pathogenic Yersinia

108 species for evidence of microevolution, and evaluated how the different isoforms

109 impacted the outcome of systemic sub-acute yersiniosis in a small animal model. Our

110 studies reveal that some YopJ residues differing between the species have been

111 subjected to evolutionary pressure. Reversion of a positively selected residue to the

112 ancestral one yielded a YopJ isoform with enhanced cytotoxicity, but one that markedly

113 attenuated Y. pseudotuberculosis virulence in animals. Conversely, loss of YopJ due to

114 catalytic inactivation or deletion rendered Y. pseudotuberculosis strains non-cytotoxic 
115 but hypervirulent. Chemical inhibition of macrophage death during in vivo infection also

116 enhanced Y. pseudotuberculosis virulence. Our results indicate that YopJ has evolved

117 towards diminished ability to induce macrophage cell death and that YopJ-induced

118 death is detrimental for $Y$. pseudotuberculosis infection. This may also suggest that

119 some level of YopP/J-induced death is beneficial to the genus, perhaps by allowing 120 persistence in an unknown reservoir.

122 Results

124 YopJ has been positively-selected in Y. pestis and Y. pseudotuberculosis for 125 reduced cytotoxicity and enhanced virulence

126 The yopP/J gene has been maintained in the genomes of all strains of human

127 pathogenic Yersinia species sequenced to date $(5,32,33)$. This conservation is 128 suggestive of an important role for the YopJ protein in the natural setting. Although

129 YopJ homologs are found in the genomes of all 3 human pathogenic Yersinia species, 130 sequence conservation differs across the length of the molecule. Some of the 131 sequence polymorphisms group $Y$. pestis and $Y$. pseudotuberculosis to the exclusion of $132 Y$. enterocolitica (the expectation), while some other polymorphisms do not cleanly 133 follow the predicted phylogeny of the organisms (Figure 1A). We investigated whether

134 or not these divergent residues show evidence of positive selection using a likelihood 135 ratio test comparing support in the data for various models of evolution (either allowing 136 for selection or imposing a nearly neutral model of evolution) $(34,35)$. This analysis 137 identified sites under positive selection (that is, ancestral sequence reconstruction and 
138 the number and kind of differences at each residue suggested that $\mathrm{dN} / \mathrm{d} S>1$,

139 Supplementary Tables 1,2) and included residue 177, which is a leucine in $Y$.

140 enterocolitica and $Y$. pestis KIM but a phenylalanine in the other $Y$. pestis homologs

141 examined and all the Y. pseudotuberculosis YopJ homologs (Figure 1B). Interestingly,

142 the YopJ ${ }^{\mathrm{F} 177 \mathrm{~L}}$ isoform was recently described to have enhanced activity relative to the

143 YopJ $^{\mathrm{F} 177}$ protein, promoting phosphorylation of $\mid \kappa \mathrm{K}-\alpha$, increased binding to $\mathrm{IKK} \beta$, and

144 causing enhanced macrophage cytotoxicity (26).

146 The existence of a hypercytotoxic YopJ variant allowed us to query if enhanced YopJ

147 activity altered $Y$. pseudotuberculosis virulence in a small animal model of systemic

148 subacute illness. Naïve mice rapidly succumb to infection with virulent $\mathrm{Y}$.

149 pseudotuberculosis. Therefore, in order to better understand the phenotypes in this

150 study we utilized a strain deficient in KsgA that had previously been shown to have a

151 slower replication rate than wild-type $\mathrm{Y}$. pseudotuberculosis due to a loss of

152 demethylation of 16s rRNA (Mecsas, Bilis, and Falkow, 2001, Mangat and Brown). We,

153 and others, have also documented that this strain is attenuated in vivo (Mecsas Bilis,

154 and Falkow 2001, Bergman, et al. 2009). Furthermore, we utilized the intravenous

155 route of infection in order to investigate the role of YopJ after $Y$. pseudotuberculosis has

156 disseminated to distal target tissues. As reported previously, YopJ ${ }^{\mathrm{F} 177 \mathrm{~L}}$ shows increased

157 cytotoxicity for macrophages relative to the YopJ ${ }^{\mathrm{F} 177}$ isoform (Fig. 2A). Using the

158 attenuated strain as our baseline background strain $\left(k s g A^{-}\right)$, we observed that $k s g A^{-}$

159 bacteria expressing YopJ ${ }^{\mathrm{F} 177 \mathrm{~L}}$ were more attenuated for virulence than the parental

$160 \mathrm{ksg} \mathrm{A}^{-}$strain, as demonstrated by the $100 \%$ survival rate of mice exposed to the $k s g A^{-}$ 
161 yopJ $J^{F 177 L}$ strain (Figure 2B). Increasing the inoculum dose did not reverse the strain's 162 complete attenuation (data not shown). These results indicate that the YopJ ${ }^{\mathrm{F} 177 \mathrm{~L}}$ -

163 containing isoform, attenuates virulence in the derived $Y$. pseudotuberculosis strains,

164 correlating with the enhanced cytotoxicity conferred by this variant.

166 Y. pseudotuberculosis strains lacking functional YopJ display increased

167 virulence in vivo

168 Given that a hypercytotoxic YopJ isoform attenuated Y. pseudotuberculosis illness in 169 mice, we predicted that the absence of YopJ would enhance the organism's virulence.

170 To test this hypothesis, we constructed an isogenic yopJ deletion strain in the $\mathrm{ksgA}^{-}$

171 background, and confirmed that $k s g A^{-} \Delta y o p J$ bacteria were non-cytotoxic for bone-

172 marrow-derived macrophages (Figure 3A). Consistent with the negative correlation

173 between cytotoxicity and virulence, mice inoculated with the $k s g A^{-} \Delta y o p J$ strain died

174 significantly sooner than those challenged with the $k s g A^{-}$strain (Figure 3B), with

175 kinetics similar to the parental $\mathrm{ksgA}^{+}$strain (36). Confirming that the enhanced virulence

176 phenotype of the $k s g-4 y o p J$ strain was due to the yopJ deletion, a strain rescued for the

177 genomic $\Delta y o p J$ lesion by allelic exchange (yop $J^{\text {repaired }}$ ) caused a mortality rate identical

178 to the parental $k s g A^{-}$strain in animals (Supplementary Figure 1).

180 The enzymatic activity of $Y$. pseudotuberculosis YopJ has been mapped to a triad of 181 residues - histidine 109, glutamate 128, cysteine $172(10)$. We asked if the virulence 182 phenotype of a strain carrying the catalytic yop ${ }^{C 172 A}$ mutation mimicked that observed 183 with the isogenic $\triangle y o p J$ strain. Similar to previous reports, the $k s g A^{-} y o p J^{C 172 A}$ strain was 
184 unable to kill cultured macrophages (Figure 3A) (37). Like $k s g A^{-} \Delta y o p J$ bacteria, $k s g A^{-}$

yopJ $J^{C 172 A} Y$. pseudotuberculosis displayed increased virulence in animals relative to the

186 parental strain (median time to death day 11 versus 12, respectively). Interestingly,

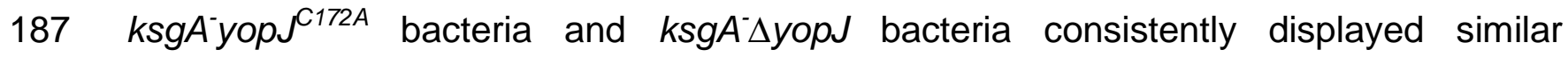

188 virulence and median times to death in multiple mouse survival assays (Figure 3B and

189 3C). Taken together, these results indicate that either the absence of YopJ or the

190 presence of inactive YopJ renders an attenuated strain of $Y$. pseudotuberculosis more

191 virulent in vivo.

193 The YopJ ${ }^{\mathrm{F} 177 \mathrm{~L}}$ isoform attenuates bacterial burden and increases host cell death 194 in vivo

195 To further understand the pathogenesis of the different YopJ-expressing strains in vivo, 196 we examined the kinetics of bacterial colonization in the spleen and liver post-challenge,

197 examining burden at days $1,3,9$, and 11 post-challenge. This analysis revealed two 198 trends. First, at later time points, mice exposed to the $k s g A^{-}$yopJ ${ }^{F 177 L}$ strains carried 199 lower burdens of splenic and hepatic bacteria than mice exposed to the parental $k s g A^{\text {, }}$ $200 k s g A^{-} \Delta y o p J$, and $k s g A^{-} y o p J^{C 172 A}$ strains (Figure 4A, B). Second, the number of 201 YopJ $^{\mathrm{F} 177}$ and YopJ-deficient bacteria (both YopJ and YopJ ${ }^{\mathrm{C172A}}$ mutants) generally 202 increased over the 11 day time course in target organs (Figure 4A, B), whereas the $203 k \operatorname{kA}^{-}$yop $J^{F 177 L}$ bacteria were either slower to accumulate in tissues (liver, Figure 4A) or 204 diminished during this time frame (spleen, Figure 4B). These results are consistent with 205 YopJ triggering host immune responses that inhibit bacterial replication and/or remove 
206 bacteria from the tissue, while the absence of YopJ activity allows the bacteria to

207 replicate unchecked in tissues.

209 In addition to causing macrophage cytotoxicity, YopJ can also inhibit macrophage

210 production of cytokines (38-41), such that the increased mortality of mice exposed to

$211 k s g A^{-}$bacteria carrying either a null or inactive yopJ allele could result from a massive

212 overproduction of cytokines, also known as a cytokine storm (42-44). However, we did

213 not find any evidence indicating that the absence of functional YopJ triggers a mortality-

214 inducing cytokine storm in vivo (Supplementary Figure 2).

216 To determine if cell death levels in vivo recapitulated what we had observed with

217 cultured macrophages exposed to the different $Y$. pseudotuberculosis strains, we used

218 the TUNEL assay to detect dead mammalian cells in tissue sections from colonized

219 mice. Mice were sacrificed at day 3 post-inoculation for cell death evaluation to ensure

220 equivalent burden levels between mice inoculated with the different strains (as observed

221 in Figure 4). This analysis revealed that at 3 days post infection, spleens containing

$222 k s g A^{-}$(WT YopJF177) or $k s g A^{-}$yopj ${ }^{F 177 L}$ bacteria had increased levels of $\mathrm{TUNEL}^{+}$cells

223 as compared to spleens containing the $k s g A^{-} \Delta$ yopJ bacteria (Figure 5 A-D), although

224 the strain expressing catalytically dead YopJ did not perfectly phenocopy the $\mathrm{ksgA}^{-}$

$225 \Delta y o p J$ strain (Figure 5D). These results indicated that the increased survival of mice

226 infected with $k s g A^{-} y o p J^{F 177 L}$ was significantly correlated with the amount of TUNEL

227 staining present in their spleens at day 3 post infection. Conversely, a decrease in the 
228 amount of TUNEL staining present in the spleens at this time point was associated with

229 the early death of mice infected with either $k s g A^{-} \Delta y o p J$ or with $k s g A^{-}$yopJ ${ }^{C 172 A}$.

231 Suramin inhibits Yersina-induced macrophage cytotoxicity and enhances

232 virulence in vivo.

233 Our results suggest that YopJ-induced cytotoxicity is detrimental to $Y$.

234 pseudotuberculosis pathogenesis, such that enhancing or inhibiting of host cell death in

235 vivo should impair or promote $Y$. pseudotuberculosis virulence, respectively. To test this

236 hypothesis, we first considered if artificially increasing macrophage death in mice

237 exposed to YopJ-null Y. pseudotuberculosis would rescue the mice from illness.

238 Clodronate-containing liposomes are commonly used to deplete macrophages in vivo -

239 depletion results because the clodronate induces global macrophage death (45); we

240 confirmed that mice exposed to clodronate liposomes showed massive levels of

241 apoptotic cells in tissues (data not shown). We inoculated mice with $k s g A^{-} \Delta y o p J ~ Y$.

242 pseudotuberculosis and 6 hours later, delivered a one-time injection of clodronate

243 liposomones. The liposome-treated animals showed a slightly increased rate of

244 mortality as compared to mock-treated animals (Supplementary Figure 3), suggesting

245 that the global depletion of macrophages masked any consequence of increased

246 macrophage apoptosis.

248 We next attempted to diminish host cell death levels in vivo, to determine if this would

249 enhance $Y$. pseudotuberdulosis virulence. We turned to the apoptosis inhibitor, suramin,

250 which is a polysulfonated urea derivative capable of inhibiting death receptor-induced 
251 apoptosis and apoptosis-mediated liver damage (46, 47). Suramin blocked Yersina

252 induced death of cultured macrophages in a dose-dependent manner (Figure 6A), at

253 the same levels previously shown to block hepatic cell cytotoxicity induced by death

254 receptors CD95, TRAIL-R1 and TRAIL-R2 (46). To evaluate how suramin treatment

255 affected $Y$. pseudotuberculosis virulence in vivo, mice were inoculated with bacteria,

256 then injected with suramin 30 minutes to 1 hour post-inoculation. Suramin had no effect

257 on naïve mice, but dramatically increased mortality of mice exposed to $k s g A^{-}$bacteria

258 (Figure 6B). This effect was YopJ-independent, however, as mice inoculated with $\mathrm{ksgA}^{-}$

$259 \Delta y o p J$ bacteria and subsequently injected with suramin showed a similar increase in

260 time-to-death (Figure 6B). Strikingly, gross pathological differences were apparent after

261 examination of $\mathrm{H} \& \mathrm{E}$ stained liver sections taken from $\mathrm{ksg} A^{-}$-infected mice treated either

262 with suramin or PBS. The suramin-treated/infected mice had significantly fewer

263 microabcesses visible in liver sections when compared to PBS-treated/infected mice

264 (Figure 6C-E). Confirming that suramin successfully impaired host cell death, liver

265 sections taken from suramin-treated mice at 3 days post-bacterial inoculation showed 266 significantly fewer TUNEL+ cells within abcesses than untreated mice (Figure 6F-H).

267 These results demonstrate that inhibition of host cell death dramatically worsens the

268 survival outcome for mice experiencing Y. pseudotuberculosis-caused illness, and

269 strongly supports the premise that host cell death protects the host and checks the

270 pathogen.

271

272 Discussion 
274 Two surprising things emerge from our study. First, positive selection of $\mathrm{YopP} / \mathrm{J}$

275 residues has occurred directionally with Yersinia evolution, and has yielded an isoform

276 with a diminished ability to induce macrophage cell death. Second, YopJ function is

277 inversely related to bacterial pathogenesis - a hypercytotoxic YopJ variant attenuates

278 Yersinia virulence in mammals, while non-functional YopP/J isoforms (or null alleles)

279 confer hypervirulence in the context of sub-acute infection. The evolutionary forces that

280 selected for bacteria with reduced YopJ activity or secretion are obscure, but this

281 obscurity does not negate that positive selection of YopP/J codons has indeed occurred

282 and these polymorphisms influence the degree of $\mathrm{YopP} / \mathrm{J}$-induced macrophage death

283 and/or Yersinia virulence towards animals (Figure 1, see also $(24,26,48,49)$ ). While

284 we observed the YopJ phenotype in a model of sub-acute Y. pseudotuberculosis illness

285 in inbred mice, we speculate that the selective niche was/is necessarily a warm-blooded

286 wild animal. This speculation is based on the knowledge that YopJ and other Yops are

287 not expressed at the ambient temperatures typical of fleas and soil $(50,51)$, the other

288 niches known to harbor $Y$. pestis (52), such that YopJ likely evolved to target

289 mammalian proteins.

290

291 How is YopJ activity diminishing Y. pseudotuberculosis virulence? Recent evidence has

292 shown that YopJ can block innate signaling interfering with TGF- $\beta$-activated kinase 1

293 (TAK1) in addition to interfering with NFKB signaling and MAPK pathways (53-56).

294 YopJ blockade of the aforementioned signaling events and in the presence of TRIF or

295 TNF signaling has been proposed to trigger receptor-interacting protein kinase 1

296 (RIPK1) and caspase-8 dependent apoptosis $(55,57,58)$. Collectively, the above 
297 studies have shown that Yersinia mediated RIPK1/caspase-8 mediated apoptosis can

298 be protective for the host. Although the precise mechanism of Yersinia induced cell

299 death was not addressed in this study, our results similarly suggest that tailoring

300 Yersina's ability to induce host cell cytotoxity may have an impact on the in vivo

301 pathogenesis. We further speculate that the mechanism is similar to the one we

302 observed previously in our studies of CD8+ $T$ cell-mediated clearance of $Y$.

303 pseudotuberculosis-associated target cells (59). In this model, bacteria expressing

304 ancestral or hyperfunctional YopJ attach to the host cell and inject the YopJ protein,

305 leading to host cell death. As dead host cells are rapidly efferocytosed by neighboring

306 activated phagocytes, the attached bacteria are also removed in the process of

307 efferocytosis, leading to pathogen clearance (Figure 7A). In contrast, bacteria

308 expressing no YopJ or catalytically dead YopJ would fail to induce host cell death,

309 meaning the host cell would not be removed and bacteria could persist longer (Figure

310 7B).

312 Given that the YopJ activity can be detrimental to Yersinia virulence, what then is the

313 purpose of YopJ-induced macrophage death for Yersinia, when the absence of YopJ so

314 clearly can increase Yersinia virulence during sub-acute illness? The continued

315 maintenance of the yopJ gene in the $Y$. pseudotuberculosis and $Y$. pestis genomes, the

316 latter of which has undergone marked decay $(5,6,32)$, suggests that the existence of a

317 niche where YopJ function remains beneficial to $Y$. pestis. One possibility is that YopJ's

318 beneficial or detrimental effects on bacterial virulence depend on the host tissue

319 environment. This speculation is supported by prior observations that YopJ-null $Y$. 
320 pseudotuberculosis bacteria have mild defects in virulence via oral inoculation, but no

321 defects via parental administration (18, 20, 24), suggesting that YopJ promotes

322 extraintestinal dissemination of Yersinia or is irrelevant in systemic tissues during acute

323 infection, a hypothesis supported by recent observations that YopJ alters intestinal

324 permeability and promotes Yersinia extraintestinal dissemination (24, 60). Other

325 findings also point to a role for YopJ in the initial local infection site (25). Additionally,

326 the role of YopJ in Y. pestis has been shown to be critical for dissemination and in

327 triggering necroptosis rather than apoptosis. This study also showed that a $\Delta$ YopJ

328 strain of $Y$. pestis led to host survival rather than death as has been observed with

$329 \Delta$ YopJ strains of $Y$. pseudotuberculosis $(57,61)$. Our findings with sub-acute systemic

330 illness, however, demonstrate that YopJ actually hinders or impairs Yersinia virulence in

331 systemic tissues. We speculate that YopJ activity serves as self-regulating mechanism

332 for Yersinia pathogenesis by allowing bacterial persistence in a resistant host or tolerant

333 tissue, possibly in a relationship approaching commensalism or at least mild parasitism.

334 In other words, an existence comparable to that observed with other chronic illness-

335 causing pathogens - for example, Salmonella typhi, which persists in gall bladders and

336 can be shed to dissemination to new environments and hosts. Another Yersinia Yop can

337 also subvert host immune recognition to promote bacterial virulence - YopK inhibits

338 inflammasome recognition of the Yersinia type III secretion system and thus prevents

339 bacterial clearance (7), although it has been proposed that YopK acts by regulating

340 T3SS translocation, rather than by direct activity towards target proteins within the host

341 cytoplasm $(62,63)$. Additionally, there is one report demonstrating that loss of YopT 
342 renders $Y$. enterocolitica hypervirulent (23). It may be that some Yops act to indirectly

343 counter those Yops that promote virulence (i.e. YopE, YopH ).

344

345 Our observations of mice exposed to non-cytotoxic $k s g A^{-}$bacteria, and of mice treated 346 with the death inhibitory chemical suramin during Y. pseudutuberculosis infection,

347 strongly suggest that host cell death is beneficial for host survival and detrimental to 348 bacterial replication and/or existence. Our experiments clearly show that suramin349 treated $/ \mathrm{ksg} A^{-}$-infected animals have a marked reduction in dead host cells $\left(\mathrm{TUNEL}^{+}\right)$, 350 suggesting that the diminished apoptosis plays at least a partial role in the increased 351 susceptibility of suramin-treated animals to infection. Suramin has also been shown to

352 inhibit cytotoxicity, decrease leukocyte infiltration, and dampen cytokine responses in 353 other in vivo rodent models $(64,65)$. Therefore, it must be acknowledged that suramin

354 has many potential uses and targets due to its complex pharmacology that may also be 355 contributing to the results that we have observed with our Yersinia infection model (66).

356 Our efforts to reduce host cell death levels with caspase inhibitors during in vivo

357 infection were unsuccessful (data not shown), perhaps due to functional redundancy in

358 the host cell death program components or the known consequence of increased 359 necrosis/necroptosis following caspase inhibition (67).

$361 \mathrm{YopP} / \mathrm{J}$ has homologues in other bacterial pathogens of animals(68), including Vibrio 362 parahaemolyticus (VopP/A) (69, 70), Aeromonas salmonicida (AopP) [60], and 363 Bartonella quintana strain Toulouse (YopP) (71). One interesting YopJ homologue is 364 AvrA, which is found in numerous species, subspecies and serovars of the genus 
365 Salmonella(33, 72). Like YopJ, AvrA is an deubiquitinase and acetyltransferase capable

366 modifying and inhibiting MAPKK and kinases in the JNK and NFKB signaling pathways

367 (73, 74), leading to modulation of host cell inflammatory responses in the intestine $(75)$.

368 Interestingly, unlike YopJ, AvrA actually prevents apoptosis in host cells (74),

369 suggesting that sequence differences between the two proteins may explain the

370 divergence in function. Although AvrA does possess a leucine at the position that aligns

371 with YopJ residue 177, suggesting that AvrA should be hyperfunctional relative to WT

372 YopJ $\left(\right.$ YopJ $\left.^{\mathrm{F} 177}\right)$, prior studies have shown that AvrA affects neither cytokine expression

373 nor plays a role in macrophage killing when expressed by either Salmonella or Yersinia

374 (76). However, it should be noted that the avrA alleles used in these studies all possess

375 a three nucleotide deletion that results in the absence of a leucine residue at position

376139 (77), also data not shown), which may explain why AvrA reportedly differs from

377 YopJ in activity and function. However, regardless of the differences in sequence and

378 tissue culture cell interactions, AvrA has two major features in common with YopJ -

379 ability to attenuate virulence (74) and promote chronic infection [69] in mouse models of 380 salmonellosis.

382 The ability of YopJ and AvrA to attenuate bacterial virulence is a feature typical of those 383 YopJ homologues found in plant-associated bacteria. YopJ is a founding member of the 384 YopJ/HopZ/AvrRxv superfamily - a family of T3SS-translocated proteins, expressed by 385 both bacterial plant pathogens and symbionts, that are recognized by plant resistance

$386(\mathrm{R})$ proteins during a plant defense response called the hypersensitive response (HR)

387 (68). Induced host cell death is a critical feature of HR, and serves to limit spread of the 
388 bacterium beyond the initial infection site (78). YopJ homologues in plant-associated

389 bacteria induce plant cell death in diverse hosts, including Arabidopsis, soybean, rice,

390 tobacco and pepper plants, among others, by targeting specific plant proteins for

391 modification (68). The requirement of a common catalytic triad suggests the plant YopJ

392 homologues have similar enzymatic activity as YopJ. Supporting this, PopP2 from

393 Ralstonia solanacearum has been shown to acetylate the Aradopsis RRS1-R resistance

394 protein [71], Xanthomonas campestris pathovar vesicatoria AvrXv4 is a SUMO protease

395 (79), and members of the HopZ family from Pseudomonas syringae have been shown

396 to have protease or acetyltransferase activity $(31,80)$.

398 Another observation from our studies is reminiscent of plant $\mathrm{R}$ protein recognition of 399 effectors. R proteins sense "altered self" in several ways -1) direct modification of the R

400 proteins by injected bacterial effector proteins, 2) indirect recognition of effector protein-

401 driven modifications of other host proteins or 3) indirect recognition of host cell

402 molecules released in effector translocation or bacterial infection (81). We find it 403 intriguing that bacteria expressing YopJ ${ }^{\mathrm{C172A}}$ did not phenocopy the YopJ bacteria for 404 mouse mortality, and were slightly attenuated relative to the YopJ bacteria. This has 405 been seen before with YopO/YpkA - in a study of YopO/YpkA mutant strains - $Y$. 406 pseudotuberculosis expressing non-functional YopO was attenuated, whereas a YopO407 null strain was unaffected for virulence (82). We speculate that a non-functional YopJ 408 protein may be perceived differently by the host than either a functional YopJ or the 409 absence of YopJ, perhaps due to host recognition of the YopJ ${ }^{\text {C172A }}$ protein itself or 410 recognition of $\mathrm{YopJ}^{\mathrm{C172A}}$ binding to target host proteins. This recognition would then 
411 induce a cytosolic innate immune response to the foreign (albeit inactive) YopJ protein.

412 This speculation remains to be addressed.

414 Phylogenetic and phylogenomic analyses are powerful approaches to identify

415 signatures of molecular evolution in the genes and genomes of bacterial pathogens. A

416 hallmark paper from Ma et al. determined that the C-terminus of HopZ, the YopJ

417 homologue found multiple $P$. syringae pathovars, has been under strong positive

418 selection (31), providing further evidence that bacterial effectors that modulate host cell

419 death are shaped by strong evolutionary forces. Interestingly, of the 14 pathovar HopZ

420 sequences examined, all possessed a leucine at the position corresponding to YopJ

421177 (31), suggesting that expression of a highly-functional HopZ is evolutionarily

422 advantageous to multiple $P$. syringae pathovars. A recent phylogenomics study of 60

423 Chlamydia trachomatis strains detected signatures of positive selection in multiple T3SS

424 effectors, and also revealed that this selection is driving $C$. trachomatis evolution

425 towards niche-specific adaptations (colonization of particular cell types or tissues)(30). It

426 is almost certain that global or gene-specific analyses of molecular evolution in bacterial

427 effector proteins will reveal evidence of positive selection, even if the selective forces

428 and niches remain obscure.

430 Our work extends the findings of two recent Yersinia phylogenomic studies of note. Gu

431 et al. examined the evolution and divergence of multigene families from 5 Yersinia

432 strains (4 Y. pestis, 1 Y. pseudotuberculosis) and found evidence of functional

433 diversities in genes associated with pathogenicity (83). While suggestive of positive 
434 selection, the authors did not individually analyze Yops for microevolutionary signatures.

435 In the second study, Cui et al. analyzed the genomes of $133 \mathrm{Y}$. pestis strains and

436 identified 2,326 single-nucleotide polymorphisms (SNPs) that appear to have been fixed

437 by neutral evolution rather than Darwinian selection (84). However, the authors only

438 analyzed SNPs from the core-genome of $Y$. pestis, not the accessory genome that

439 includes the extrachromosomal plasmid encoding the yop genes, meaning that yopJ 440 was not included in their analysis. Others have found at least 1 chromosomally-encoded

441 Yersinia protein has undergone positive selection at the codon level, as analysis of

442 OmpF porin sequence from 73 different Yersinia strains found positively selected 443 residues in several surface-exposed OmpF domains (85). As such, our findings

444 constitute the first description of diversifying selection in the accessory genome of any

445 Yersinia species member. Although our analysis were performed on only a small subset

446 of Yersinia YopP/J sequences, the site identified here, codon 177, showed a significant

447 level of positive selection, indicating the validity of our findings.

449 Our observations prompt the intriguing speculation that other Yops will also show 450 evidence of molecular evolution. Given that the number of translocated Yersinia 451 proteins is low ( 6-8 proteins), it seems likely that the importance of each individual 452 effector is therefore increased, such that sequence divergence in response to any 453 selective pressure would be greater. Microevolution within the sequences of other Yops, 454 which generally function as pro-virulence factors, could result in Yops with increased 455 functional abilities that confer increased virulence to individual strains or species. If true, 
456 it would present an interesting tug of war between pro-virulence Yops and anti-virulence

$457 \mathrm{YopP} / \mathrm{J}$, the outcome of which would likely dependent on the niche.

459 Finally, the degree of positive selection in host proteins targeted by YopJ or other Yops

460 is completely unknown. Recent observations of the molecular "arms race" between host

461 and viral proteins demonstrated that the host anti-viral protein PKR (protein kinase R)

462 has been subjected to intense episodes of positive selection in primates, in order to

463 evade viral mimics of the PKR binding partner elF2 $\alpha$ (86). Regarding the latter, it is

464 interesting to note that the activities both YopJ and YpkA/YopO converge on a kinase of

465 elF2 $\alpha$ (87). Further identification of YopP/J-specific target proteins and evaluation of

466 sequence divergence through the primate lineage will reveal the degree of YopP/J-

467 driven evolution of host immune response proteins.

469 Materials And Methods

470

\section{Bacterial Strains and Growth Conditions}

472 Strains used in this study are indicated in Table 1, primers used for strain construction

473 are indicated in Table 2. Lysogeny Broth (LB) and LB agar plates were made using the

474 Lennox formulation $(5 \mathrm{~g} / \mathrm{L} \mathrm{NaCl})$, and when necessary, selective antibiotics included at

475 the following concentrations: kanamycin $30 \mu \mathrm{g} / \mathrm{mL}$, ampicillin $100 \mu \mathrm{g} / \mathrm{mL}$, irgasan

$4761 \mu \mathrm{g} / \mathrm{mL}$, chloramphenicol $20 \mu \mathrm{g} / \mathrm{mL}$. The $Y$. pseudotuberculosis strain YPIII plB1 was

477 the parent of all strains described here. The $k s g A^{-}$strain has been described and used

478 by us previously $(88,89)$ and contains a kanamycin-resistance-encoding transposon 
479 inserted into the $k s g A$ gene. To generate the $k s g A^{-} \Delta y o p J$ strain, we used a previously-

480 described suicide vector construct, pCVD442- $\Delta$ yopJ (kind gift of Dr. Joan Mecsas, Tufts

481 University), in which the upstream and downstream DNA flanking yopJ open-reading

482 frame was fused together with only the first and last codon of yopJ remaining (90).

483 Introduction of this unmarked yopJ deletion allele into the $k s g A^{-}$genome was

484 accomplished via allelic exchange, using pCVD442-encoded ampicillin and sucrose

485 resistance as the selectable and counter-selectable markers, respectively. Briefly, the

486 suicide vector was transferred from Escherichia coli strain SM10גpir to $Y$.

487 pseudotuberculosis strain $\mathrm{ksgA}^{-}$by conjugation, and ampicillin-resistant/irgasan-

488 resistant integrants selected. Integrants were grown overnight in the absence of plasmid

489 selection, then dilutions of the culture placed on counter-selection agar plates

490 containing $10 \%$ sucrose and lacking salt. Sucrose-resistant colonies were confirmed to

491 be ampicillin-sensitive and the presence or absence of the $\Delta y o p J$ determined by PCR

492 screening. To generate yopJ alleles carrying mutations in codons 172 and 177, a

493 fragment of the yopJ gene was first cloned by PCR into pACYC184, then site-directed

494 mutagenesis performed using long-range PCR with primers containing the mutant

495 sequence and Dpn to remove the vector template. After confirming the sequence

496 change, the mutated yopJ sequence was transferred to pCVD442, allelic exchange

497 performed as described above, and the presence or absence of the mutant yopJ

498 codons was determined by sequencing amplified genomic DNA. Bacteria were grown

499 for cultured macrophage experiments as follows. After 2 days growth on LB agar plates

500 from glycerol stocks, single colonies from the indicated strains were inoculated into 2

$501 \mathrm{~mL}$ LB broth and incubated at $26^{\circ} \mathrm{C}$ for $15-18$ hours with rotation. Overnight cultures 
502 were back-diluted to an estimated $\mathrm{OD}_{600}$ of 0.2 into low-Ca ${ }^{2+}$ medium (2XYT broth 503 containing $20 \mathrm{mM}$ of the $\mathrm{Ca}^{2+}$ chelator sodium oxalate and $20 \mathrm{mM} \mathrm{MgCl}$, then grown

504 with constant rotation for 1.5 hours at $26^{\circ} \mathrm{C}$ and 1.5 hours at $37^{\circ} \mathrm{C}$. Cultures were then

505 adjusted to the desired concentration in macrophage media and used for macrophage

506 challenges as described below. Bacteria were grown for mouse experiments as follows.

507 After 2 days growth on LB agar plates from glycerol stocks, single colonies were 508 inoculated into $2 \mathrm{~mL}$ LB broth and incubated at $26^{\circ} \mathrm{C}$ for $15-18$ hours with rotation.

509 Overnight cultures were then adjusted to the desired concentration in PBS and used for 510 mouse challenges as described below (after removing a sample for accurate 511 determination of colony-forming units per $\mathrm{mL}$ i.e. $\mathrm{CFU} / \mathrm{mL}$ ).

512

513 Codon-level selection analysis of YopJ sequences across multiple

514 Yersinia lineages.

515 To investigate the evolutionary history of YopJ, orthologs were found by using reciprocal

516 blast searches across 15 sequenced genomes, including extrachromosomal elements,

517 and 2 individual yopJ loci (NC_003131.gbk, NC_003132.gbk, NC_003134.gbk,

518 NC_003143.gbk, NC_004088.gbk, NC_004838.gbk, NC_005810.gbk, NC_005813.gbk,

519 NC_005814.gbk, NC_005815.gbk, NC_005816.gbk, NC_006153.gbk, NC_006154.gbk,

520 NC_006155.gbk, NC_008118.gbk, NC_008119.gbk, NC_008120.gbk, NC_008121.gbk,

521 NC_008122.gbk, NC_008149.gbk, NC_008150.gbk, NC_008791.gbk, NC_008800.gbk,

522 NC_009377.gbk, NC_009378.gbk, NC_009381.gbk, NC_009704.gbk, NC_009705.gbk,

523 NC_009708.gbk, NC_010157.gbk, NC_010158.gbk, NC_010159.gbk, NC_010465.gbk,

524 NC_010634.gbk, NC_010635.gbk, NC_014017.gbk, NC_014022.gbk, NC_014027.gbk, 
525 NC_014029.gbk, NC_015224.gbk, NC_015475.gbk, NC_017153.gbk, NC_017154.gbk, 526 NC_017155.gbk, NC_017156.gbk, NC_017157.gbk, NC_017158.gbk, NC_017159.gbk, 527 NC_017160.gbk, NC_017168.gbk, NC_017169.gbk, NC_017170.gbk, NC_017263.gbk, 528 NC_017264.gbk, NC_017265.gbk, NC_017266.gbk, NC_017564.gbk, NC_017565.gbk).

529 Protein sequences were aligned using Clustalw and nucleotide sequences for each

530 YopJ ortholog were aligned based on their amino acid translation (using in house 531 scripts). These nucleotide alignments were used as input to RAxML[83], where 532 maximum likelihood phylogenies were generated (GTRGAMMA model of substitution).

533 A considerable amount of change in the YopJ homologs has occurred during the 534 evolution of these pathogens; some of these changes alter protein encoding (dN, non535 synonymous nucleotide substitutions) while some do not (dS, synonymous 536 substitutions). Evidence of adaptative selection was found across the aligned ortholog 537 set by calculating the ratio of $\mathrm{dN} / \mathrm{dS}$ in pairwise comparisons of orthologs. In order to 538 identify those YopJ residues under selection and the direction and strength of selection 539 at the codon level, the frequency of nonsynonymous and synonymous changes and 540 their ratio ( $\mathrm{dN} / \mathrm{dS}$ or $\omega$ ) were calculated using Phylogenetic Analysis by Maximum 541 Likelihood (PAML v4.7) software using the Goldman and Yang amino acid substitution 542 model (codeML) and these same nucleotide alignments [84]. To increase the sensitivity 543 of our analysis we also calculated variable dN/dS $(\omega)$ over all sites (models M7 vs. M8) 544 and used the likelihood ratio test to identify statistically significant evidence for 545 diversifying selection $\left(\chi^{2}=14 ; \mathrm{df}=2 ; \mathrm{p}<0.01\right)$. In house Perl scripts were used to 546 parse the codeML output files to identify residues predicted to have undergone 
547 diversifying selection in YopJ (using maximum likelihood ratio tests before analyzing the

548 results).

550 Derivation of Bone Marrow Macrophages

551 Bone marrow-derived macrophages (BMDM) were generated by culturing bone marrow

552 cells freshly-harvested from the femurs and tibias of C57BL/6 mice in supplemented 553 DMEM as previously described (59). Macrophages were harvested on day 6 of the

554 derivation protocol and seeded at a density of $5 \times 10^{4}$ cells/100 $\mu \mathrm{L} /$ well of a 96 well plate 555 in supplemented DMEM lacking antibiotics and allowed to adhere to the plastic 556 overnight. Occasionally, at day 6, macrophages were cryofrozen in 5\% DMSO/95\%

557 fetal-bovine serum (FBS) at a concentration of $1 \times 10^{7}$ cells $/ \mathrm{mL}$ and subsequently thawed 558 for seeding.

559

560 Macrophage Infections, Treatments and Cytotoxicity Assay

561 Y. pseudotuberculosis, grown as described above, was added to adherent 562 macrophages at a multiplicity of infection (MOI) of 100:1 in DMEM without phenol red +

$5631 \%$ FBS for 45 minutes to 1 hour. Gentamicin was added to a final concentration of 100

$564 \mu \mathrm{g} / \mathrm{mL}$ and the cells were allowed to incubate an additional 2 hours. For suramin 565 experiments, BMDM were first pretreated with various concentrations of suramin 566 (Sigma, St. Louis, MO) for 1 hour, then exposed to bacteria at an MOI of 100:1 in the 567 presence or absence of suramin at the indicated concentrations. Macrophage death 568 was evaluated by detection of the cytoplasmic enzyme lactate dehyrogenase (LDH) in 569 the culture supernatants similarly as previously described(59). Briefly, macrophages 
570 were spun down at $250 x g$ for 2 minutes and $50 \mu \mathrm{L}$ supernatant carefully removed from

571 each well, transferred to a new 96-well plate, and immediately assayed for the presence

572 of LDH using the Cytotox 96 Assay kit (Promega, Madison, WI) according to the

573 manufacturer's recommendations. Note that controls cells were treated with $1 \%$ Triton-X

574100 to liberate cytoplasmic contents approximately 15 minutes prior to supernatant

575 harvest. $50 \mu \mathrm{L}$ of reconstituted substrate solution (containing 2-(4-lodophenyl)-3-(4-

576 nitrophenyl)-5-phenyl-2H-tetrazolium chloride, or INT) was added to the harvested

577 supernatants, the reaction incubated at room temperature in the dark for 30 minutes,

578 then the enzymatic conversion of INT into a red formazan product terminated by

579 addition of $50 \mu \mathrm{L}$ stop solution ( $1 \mathrm{M}$ acetic acid) and excess bubbles in each well

580 punctured. Absorbance was measured at $490 \mathrm{~nm}$ in a BioTek Synergy H4 plate reader

581 (BioTek, Winooski, VT). \% Cytotoxicity was calculated as follows: 100× [(experimental

582 release - effector T cell spontaneous release - target cell spontaneous release)/(target

583 cell maximum release - target cell spontaneous release)].

584

585 Mouse Infections and Treatments

586 6-8 week old female C57BL/6 mice were purchased from the National Cancer Institute

587 colony at Charles River. Mice were allowed to rest for 7 days after arrival, then infected

588 intravenously via tail vein injection with a $200 \mu \mathrm{L}$ inoculum containing between $3.5 \times 10^{2}$

589 and $2 \times 10^{3}$ colony-forming units (CFU) in PBS of the indicated Y. pseudotuberculosis

590 strain. Mice were then visually inspected for signs of illness including lethargy and

591 piloerection and weighed daily to monitor the disease progression. For suramin

592 experiments, mice were infected as before, then intraperitoneally injected once with 5 
$593 \mathrm{mg}$ suramin/400 $\mu \mathrm{L}$ PBS or $400 \mu \mathrm{L}$ PBS alone 30 minutes to 1 hour post-infection. For

594 clodronate experiments, clodronate-containing liposomes were prepared as described

595 below, then $200 \mu$ of liposomes were injected intravenously 6 hours post infection. All

596 animal experiments were performed in accordance with the NIH Guide for the Care and

597 Use of Laboratory Animals and were approved by the UTHSCSA Institutional Animal

598 Care and Use Committee.

599

600 Preparation and Characterization of Clodronate Liposomes

601 Liposomes containing dichloromethylene bisphosphonate (clodronate) or control empty 602 liposomes containing phosphate buffered saline (PBS) were prepared from reported 603 protocols with slight modifications $(45,91)$. In two $500 \mathrm{~mL}$ round bottom flasks, $96 \mathrm{mg}$ 604 cholesterol (Calbiochem, San Diego, CA) was added and dissolved with $10 \mathrm{~mL}$ 605 chloroform (HPLC grade, Fisher Scientific, Fair Lawn, NJ). Then $4.14 \mathrm{~mL}$ of egg 606 phosphatidylcholine in chloroform (25 mg/ mL; Avanti Polar Lipids, Alabaster, AL) was 607 added. Lipid films were formed following removal of chloroform by rotary evaporation. 608 The lipid films were placed under vacuum for $1 \mathrm{~h}$ to remove residual chloroform. The 609 lipid films were rehydrated with $12 \mathrm{~mL}$ of $0.7 \mathrm{M}$ clodronate (Sigma Aldrich, St Louis, $610 \mathrm{MO}$ ) prepared in degassed sterile water for injection (Hospira, Lake Forest, IL) and pH 611 adjusted to 7.0, or degassed Dulbecco's PBS, pH 7.4 (Invitrogen, Carlsbad, CA). The 612 flasks were swirled until the lipids were in suspension. The lipid suspensions were kept 613 at room temperature for $2 \mathrm{~h}$ with occasional swirling, sonicated in a water bath for 4 614 minutes (Branson, Danbury, CT) and then kept at room temperature for $2 \mathrm{~h}$. The 615 liposome samples were then extruded through polycarbonate filters $(2 \mu, 2$ times; $1 \mu, 4$ 
616 times) using an extruder (Lipex, Northern Lipids, Vancouver, Canada) and collected in a

617 new tube. After flushing the liposome samples with argon, the samples were stored

618 overnight at $4^{\circ} \mathrm{C}$. The next day the liposomes were transferred to microcentrifuge tubes

619 and centrifuged in an Allegra 21R centrifuge (Beckman Coulter, Brea, CA) at 15,300

$620 \mathrm{rpm}$ for 30 minutes at $10^{\circ} \mathrm{C}$. The supernatants were removed and the pellets

621 resuspended with degassed PBS. The samples were washed 4 times. After the last

622 wash, the liposome pellets were resuspended in degassed PBS to a final volume of 4.8

$623 \mathrm{~mL}$, flushed with argon and stored at $4^{\circ} \mathrm{C}$ until needed. Liposomes were used for the

624 study within 2 weeks of preparation. Liposome diameter was measured at $488 \mathrm{~nm}$ with

625 a DynaPro dynamic light scattering system (Wyatt Technology, Santa Barbara, CA).

626 The diameters for clodronate liposomes and control PBS liposomes were $968 \pm 28 \mathrm{~nm}$

627 and $790 \pm 41 \mathrm{~nm}$, respectively. Phospholipid content was measured using

628 phosphatidylcholine colorimetric assay kit (Cayman Chemical, Ann Arbor, MI) and

629 determined to be $14.5 \mathrm{mg} / \mathrm{mL}$ for the clodronate liposomes and $15.4 \mathrm{mg} / \mathrm{mL}$ for the PBS

630 liposomes. The amount of liposome-encapsulated clodronate was determined to be

$63112.7 \mathrm{mg} / \mathrm{mL}$ (45). In pilot experiments, clodronate liposomes were confirmed to induce

632 macrophage death by TUNEL staining in spleens of non-infected mice (data not

633 shown).

634

635 Organ Bacterial Burden Assay

636 At the noted times post-infection, mice were sacrificed by cervical dislocation, spleens

637 and livers aseptically removed, transferred to sterile PBS from mice at various time

638 points after infection and weighed. Tissues were mechanically disrupted using a tissue 
639 homogenizer (Omni, Marietta GA), serially diluted in sterile PBS and $100 \mu \mathrm{L}$ of the

640 dilutions plated on nutrient LB agar plates. After 48 hours at $26^{\circ} \mathrm{C}$, bacterial colonies

641 were enumerated and CFU normalized to weight of tissue in grams. Note that as each

642 animal may have had an organ weight different from the other animals, the CFU values

643 at or below the limit of detection (10 CFU per $\mathrm{mL}$ of organ homogenate) were

644 occasionally different between individual animals. The limit of detection in the spleen

645 was $(90 \mathrm{CFU} / \mathrm{g} / \mathrm{spleen}$ or $1.95 \mathrm{Log} \mathrm{CFU})$ and in the liver was (22 CFU/g/Liver or 1.33

646 Log CFU).

647

648 Cytokine Analysis

649 Cytokine analysis was performed on serum and tissue homogenates from day 3 and

650 day 9 post-inoculation. Briefly, blood was collected via cardiac puncture and allowed to 651 clot for 30 minutes. Serum was collected after centrifugation at $7000 \mathrm{rpm}$ for 7 minutes

652 and stored at $-80^{\circ} \mathrm{C}$. Cytokines were assayed using the Mouse Cytokine 20-plex panel

653 strictly adhering the manufacturer's protocol (Life Technologies, Carlsbad CA). Cytokine

654 levels were detected using a Bio-Plex 200 system and analyzed using Bio-Plex

655 Manager 6.0 software (Bio-Rad, Hercules CA).

656

657 Terminal Deoxynucleotidyl Transferase dUTP Nick End Labeling (TUNEL) Assay

658 Spleens were harvested at 3 days post-infection and were snap-frozen in the cyrostat 659 sectioning medium Tissue-Tek® O.C.T. ${ }^{\mathrm{TM}}$ (Sakura, Torrance CA). Livers were removed 660 and placed in $10 \%$ buffered formalin for at least three days and then sent to the

661 UTHSCSA Histopathology Laboratory to be embedded in paraffin and cut into 4 micron 
662 sections. Some slides with liver sections were stained with hematoxylin and eosin and 663 others were processed for TUNEL staining with the ApopTag kit as outlined below.

664 OCT-frozen spleen sections were cut with a cryostat (Thermo Scientific Shandon, 665 Waltham MA), placed on slides and allowed to air-dry overnight. The slide-affixed tissue 666 sections were then fixed in acetone for 20 seconds at room temperature, allowed to dry, 667 then wrapped in foil and stored at $-80^{\circ} \mathrm{C}$. Subsequently, sections were stained for 668 nicked DNA, to label TUNEL ${ }^{+}$cells, using the ApopTag kit with included buffers (EMD 669 Millipore, Billerica MA). Briefly, slides were removed from $-80^{\circ} \mathrm{C}$ and allowed to warm up 670 to room temperature. Slides were then fixed in $1 \%$ paraformaldehyde for 10 minutes at 671 room temperature and washed in PBS twice. Tissue sections were not allowed to dry 672 after this point. Tissue sections were then circled with a hydrophobic PapPen (Kiyota 673 International, Elk Grove Village, IL) and equilibration buffer was incubated on the 674 section for at least 10 seconds. TdT enzyme solution $(10 \%$ enzyme $+20 \%$ PBS $+70 \%$ 675 reaction buffer) was applied for 60 minutes in a humidity chamber at $37^{\circ} \mathrm{C}$. Stop solution 676 was then applied for 10 minutes at room temperature followed by three washes with 677 PBS. A solution containing anti-digoxigenin fluorescein antibody (53\% blocking solution $678+47 \%$ anti-digoxigenin fluorescein conjugate) was applied and allowed to incubate for 67930 minutes in a dark humidity chamber. Slides were then protected from light as much 680 as possible from this point forward. Slides were then washed three times in PBS and 681 mounted with ProLong Gold Antifade reagent containing DAPI (Life Technologies, 682 Carlsbad CA). Sections from a given experiment were stained on the same day. 
685 Stained tissue sections were visualized using either an EC plan neofluar 10x or Plan-

686 Apochromat 20x/.8 objective on a Zeiss Axiolmager Z1 epifluorescent microscope (Carl

687 Zeiss, Thornwood, NY). Images were captured using a Zeiss AxioXam MRm Rev3

688 and/or MRc cameras and analyzed using Zeiss AxioVision release 4.5 software.

689 Sections from a given experiment were imaged on the same day with the same

690 exposure times for image acquisition to ensure consistency between samples. ImageJ

691 (92) was used to measure the pixel intensity in each captured image.

692

693 Data and Statistical Analysis

694 Prism 5 (GraphPad Software, La Jolla CA) was used for graphing and statistical

695 analysis. Survival curves were estimated using the Kaplan Meier method and 696 significance calculated using the log-rank test. The nonparametric Mann-Whitney U test

697 and unpaired Student's t test were used to determine statistical differences between 698 groups of data from animal and tissue culture experiments, respectively. Image 699 quantification data was evaluated for significance using the Mann-Whitney U test.

700

701 Acknowledgements

702

703 We thank lan Morris and Michael Berton for use and instruction of the Zeiss Axiolmager

704 Z1 microscope. We thank Joan Mecsas, Peter Dube and Angel Cantwell for helpful

705 discussions and critical analysis of the manuscript. This work was supported by National

706 Institutes of Health, Grant AI085116 from the NIAID to M.A.B., and Grant Al110684

707 from the National Institute of Allergy and Infectious Diseases and HHMI support of R.R.I. 
709 Figure Legends

711 Figure 1. YopP/J is divergent between Yersinia species and shows evidence of positive selection

713 (A) The phylogeny of three Yersinia species ( $Y$. enterocolitica, 3 strains, $Y$.

714 pseudotubercolosis, 2 strains, and Y. pestis, 9 strains) generated using the YopJ

715 primary sequences. Bootstrap support based on 1000 replicates. Codon 177 was

716 identified as under positive selection in a Naive empirical Bayes (NEB) analysis and

717 amino acid polymorphism at that site is mapped onto the phylogeny of these Yersinia

718 strains ("L" in blue and "F" in red). (B) Alignment of the relevant region of YopP/J

719 homologs from these 14 Yersinia strains from the three human pathogenic species.

720 YopP/J was identified as having experienced positive selection at residue 177.

721

722 Figure 2. Ancestral version of YopP/J confers enhanced macrophage death and

723 attenuated virulence. (A) Bone marrow derived macrophages were exposed to either

$724 k s g A^{-}, k s g A^{-} \Delta y o p J$, or $k s g A^{-}$yop $J^{F 177 L}$ Y. pseudotuberculosis at an MOI of 100:1. LDH

725 release was measured to determine the cytotoxicity of these strains in macrophages.

726 (B) C57BL/6 mice were intravenously challenged with $1 \times 10^{3} \mathrm{CFU}$ of either $k s g A^{-}(n=12)$

727 or $k g A^{-}$yopJ ${ }^{F 177 L}(n=11)$ Y. pseudotuberculosis. Morbidity and mortality were followed

728 after challenge and data shown represents the percent survival of each group. In vivo

729 data is compiled from two independent experiments. Student's $t$ test was used to

730 analyze BMDM infections. The Kaplein-Meier method was used to generate survival 
731 curves and the log-rank test was used to calculate the significance $\left({ }^{*} p<.05,{ }^{* *} p<.01\right.$, $\left.732{ }^{* * *} p<.005\right)$.

733

734 Figure 3. Loss of YopJ reverses the attenuation phenotype of $\mathrm{ksgA}^{-} \mathrm{Y}$.

735 pseudotuberculosis. (A) Bone marrow derived macrophages were infected with either

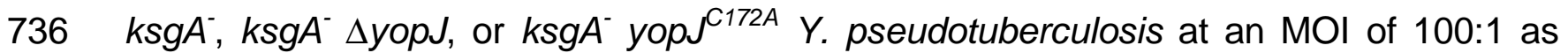

737 described in the Methods section. One of four independent experiments is shown. LDH

738 release was measured to determine the cytotoxicity of these strains in macrophages.

739 (B) C57BL/6 mice were intravenously challenged with $1 \times 10^{3} \mathrm{CFU}$ of either $\mathrm{ksgA}^{-}(n=19)$,

$740 k_{s g A^{-} \Delta y o p J}(n=22)$, or $k s g A^{-}$yop $J^{c 172 A}(n=18)$ Y. pseudotuberculosis and monitored for

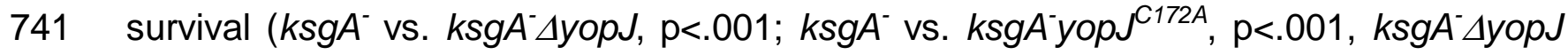

742 vs. ksgA'yopJ ${ }^{C 172 A}$, not sig.). (C) The median time until death was also assessed for

743 each experiment. In vivo data is compiled from 4 independent experiments. The

744 Student's t test was used to analyze BMDM infections. The Kaplein-Meier method was

745 used to generate survival curves and the log-rank test was used to calculate the

746 significance. The Mann-Whitney $U$ test was used to compared MTD data $747 \quad\left({ }^{*} p<.05,{ }^{* *} p<.01,{ }^{* * *} p<.005\right)$.

748

749 Figure 4. Y. pseudotuberculosis expressing YopJ ${ }^{\text {F177L }}$ show attenuated

750 colonization in vivo. (A) Liver and (B) spleen were isolated at multiple time points from

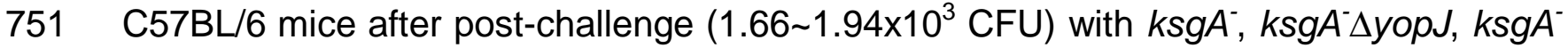

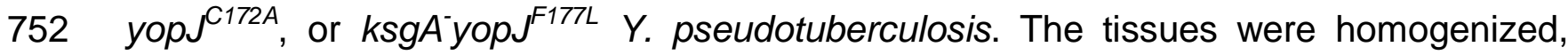

753 serially diluted and plated on LB plates. Burdens recovered in each tissue from each 
754 mouse were above the limit of detection. Data shown is from 5 mice/group and is

755 representative of two independent experiments. The Mann-Whitney $U$ test was used to

756 compare CFU data $\left({ }^{*} p<.05,{ }^{* *} p<.01,{ }^{* * *} p<.005\right)$.

Figure 5. Ancestral YopP/J variant causes increased levels of cytotoxicity in vivo.

759 6-8 week old female C57BL/6 mice were infected intravenously $\left(1 \sim 1.26 \times 10^{3}\right.$ CFU) with

760 strains of $Y$. pseudotuberculosis expressing $k s g A^{-}$; $k s g A^{-} \Delta y o p J, k s g A^{-}$yopJ ${ }^{C 172 A}$, or

$761 \mathrm{ksgA}^{-}$yop $\mathrm{F}^{\mathrm{F} 77 L}$. A-C. Spleens were removed at day 3 post infection snap frozen in OCT 762 for TUNEL staining. Row $A$ is showing TUNEL only images at $200 x$ and row $B$ is

763 showing staining of representative images for Y. pseudotuberculosis (Rhodamine Red

$764 \mathrm{X}$ ). Row $\mathrm{C}$ is depicting the merged images with DAPI (blue), TUNEL (FITC) and $Y$.

765 pseudotuberculosis (Rhodamine Red X) at a total magnification of 200x. D. Random

766 images were captured (6 from each spleen, 3 mice per group per experiment) and

767 TUNEL+ area (total pixels) per field was quantified using ImageJ software. 5D shows

768 pooled results obtained from two independent experiments. The Mann-Whitney $U$ test 769 was used to compare TUNEL data $\left({ }^{*} p<.05,{ }^{* *} p<.01,{ }^{* * *} p<.005\right)$.

770

771 Figure 6. Suramin inhibits Yersina-induced macrophage cytotoxicity and

772 enhances virulence in vivo. A. Bone marrow derived macrophages from C57BL/6

773 mice were exposed to $k s g A^{-} Y$. pseudotuberculosis at an $\mathrm{MOI}$ of 100:1 in the presence

774 or absence of suramin at different concentrations. LDH release was measured to

775 determine macrophage cytotoxicity. B. C57BL/6 mice (n=3-6/group; repeated twice)

776 were infected intravenously $\left(1.08 \sim 1.38 \times 10^{3}\right.$ CFU) with various strains of $Y$. 
777 pseudotuberculosis in the presence or absence of suramin delivered intraperitoneally

778 shortly after infection. Mice were weighed daily and monitored for signs of morbidity

$779\left(k s g A^{-}+\right.$PBS vs. $k s g A^{-}+$suramin, $p=.0042 ; k s g A^{-} \Delta y o p J+P B S$ vs. $k s g A-\Delta y o p J+$

780 suramin $p=.0005 ; k s g A-+$ suramin vs. $k s g A^{-} \Delta y o p J+$ suramin, $\left.p=.023\right)$. C. and D.

781 C57BL/6 mice ( $n=3$ per group; repeated twice) were infected intravenously with $Y$.

782 pseudotuberculosis $\mathrm{ksgA}-\left(1 \times 10^{3} \mathrm{CFU}\right)$ and treated intraperitoneally with either $5 \mathrm{mg}$ of

783 suramin or with PBS. After three days, mice were sacrificed and livers were harvested

784 and stained with H\&E, large white arrows indicate representative lesions found in the

785 sections. E. Quantification of the number of microabscesses from the entirety of the

786 H\&E-stained liver sections ( $n=3$ per group). F. and G., TUNEL-stained liver sections are

787 shown, with TUNEL+ lesions highlighted with white solid arrows. H. Quantification of the

788 degree of TUNEL positivity per microabscess ( $n=4-6$ microabscesses per liver section;

$789 n=3$ mice per group). The Kaplein-Meier method was used to generate survival curves

790 and the log-rank test was used to calculate the significance. The Student's t test was

791 used to analyze BMDM infections. The Mann-Whitney $U$ test was used to compare

792 TUNEL data $\left({ }^{*} p<.05,{ }^{* *} p<.01,{ }^{* * *} p<.005\right)$.

793

794 Fig. 7. Proposed model to explain how different YopJ proteins lead to different in

795 vivo outcomes following Y. pseudotuberculosis infection. A. Y.

796 pseudotuberculosis expressing functional YopJ (harboring either the wild type/positively

797 selected F177 or the ancestral L177) attach to the host cell and inject YopJ, leading to

798 host cell death. Efferocytosis of dead host cells by neighboring activated phagocyte also

799 removes those bacteria attached to dead host cells, leading to pathogen clearance 
801 cell death, meaning the host cell would not be removed and bacteria could persist

802 longer to cause illness. For either scenario, other factors including host innate and

803 adaptive immune responses (not shown), could also influence the balance between

804 pathogen clearance and pathogen persistence.

\section{References}

1. Fink SL, Cookson BT. Apoptosis, pyroptosis, and necrosis: mechanistic description of dead and dying eukaryotic cells. Infect Immun. 2005;73(4):1907-16. Epub 2005/03/24. doi: 10.1128/IAI.73.4.1907-1916.2005. PubMed PMID: 15784530; PMCID: PMC1087413.

810 2. Bergsbaken T, Fink SL, Cookson BT. Pyroptosis: host cell death and inflammation. Nat Rev Microbiol. 2009;7(2):99-109. Epub 2009/01/17. doi: 10.1038/nrmicro2070. PubMed PMID:

812 19148178; PMCID: PMC2910423.

813

814

815

816

817 of the caspase-1 inflammasome in Salmonella typhimurium pathogenesis. J Exp Med. 2006;203(6):1407-12. Epub 2006/05/24. doi: 10.1084/jem.20060206. PubMed PMID: 16717117; PMCID: PMC2118315.

4. Lima-Junior DS, Costa DL, Carregaro V, Cunha LD, Silva AL, Mineo TW, Gutierrez FR, Bellio M, Bortoluci KR, Flavell RA, Bozza MT, Silva JS, Zamboni DS. Inflammasome-derived IL-1 beta production induces nitric oxide-mediated resistance to Leishmania. Nat Med. 2013;19(7):909-15. Epub 2013/06/12. doi: 10.1038/nm.3221. PubMed PMID: 23749230. Andersen GL. Complete genome sequence of Yersinia pestis strains Antiqua and Nepal516: evidence of gene reduction in an emerging pathogen. J Bacteriol. 2006;188(12):4453-63. Epub 2006/06/03. doi: 10.1128/JB.00124-06. PubMed PMID: 16740952; PMCID: PMC1482938.

6. Wren BW. The yersiniae--a model genus to study the rapid evolution of bacterial pathogens. Nat Rev Microbiol. 2003;1(1):55-64. Epub 2004/03/26. doi: 10.1038/nrmicro730. PubMed PMID: 15040180.

7. Brodsky IE, Palm NW, Sadanand S, Ryndak MB, Sutterwala FS, Flavell RA, Bliska JB, Medzhitov R. A Yersinia effector protein promotes virulence by preventing inflammasome recognition of the type III secretion system. Cell Host Microbe. 2010;7(5):376-87. Epub 2010/05/19. doi: 10.1016/j.chom.2010.04.009. PubMed PMID: 20478539; PMCID: PMC2883865. 8. Garcia JT, Ferracci F, Jackson MW, Joseph SS, Pattis I, Plano LR, Fischer W, Plano GV. Measurement of effector protein injection by type III and type IV secretion systems by using a 13residue phosphorylatable glycogen synthase kinase tag. Infect Immun. 2006;74(10):5645-57. Epub 2006/09/22. doi: 10.1128/IAI.00690-06. PubMed PMID: 16988240; PMCID: PMC1594927. 9. Trosky JE, Liverman AD, Orth K. Yersinia outer proteins: Yops. Cell Microbiol. 2008;10(3):557-65. Epub 2007/12/18. doi: 10.1111/j.1462-5822.2007.01109.x. PubMed PMID: 18081726. 
841

842

843

844

845

846

847

848

849

850

851

852

853

854

855

856

857

858

859

860

861

862

863

864

865

866

867

868

869

870

871

872

873

874

875

876

877

878

879

880

881

882

883

884

885

886

887

888

889

890

2000;290(5496):1594-7. Epub 2000/11/25. doi: 10.1126/science.290.5496.1594. PubMed PMID: 11090361.

11. Sweet CR, Conlon J, Golenbock DT, Goguen J, Silverman N. YopJ targets TRAF proteins to inhibit TLR-mediated NF-kappaB, MAPK and IRF3 signal transduction. Cell Microbiol. 2007;9(11):2700-15. Epub 2007/07/05. doi: 10.1111/j.1462-5822.2007.00990.x. PubMed PMID: 17608743.

12. Zhou H, Monack DM, Kayagaki N, Wertz I, Yin J, Wolf B, Dixit VM. Yersinia virulence factor YopJ acts as a deubiquitinase to inhibit NF-kappa B activation. J Exp Med. 2005;202(10):1327-32. Epub 2005/11/23. doi: 10.1084/jem.20051194. PubMed PMID: 16301742; PMCID: PMC2212976. 13. Mittal R, Peak-Chew SY, McMahon HT. Acetylation of MEK2 and I kappa B kinase (IKK) activation loop residues by YopJ inhibits signaling. Proc Natl Acad Sci U S A. 2006;103(49):18574-9. Epub 2006/11/23. doi: 10.1073/pnas.0608995103. PubMed PMID: 17116858; PMCID: PMC1654131.

14. Mukherjee S, Keitany G, Li Y, Wang Y, Ball HL, Goldsmith EJ, Orth K. Yersinia YopJ acetylates and inhibits kinase activation by blocking phosphorylation. Science. 2006;312(5777):1211-4. Epub 2006/05/27. doi: 10.1126/science.1126867. PubMed PMID: 16728640.

15. Mittal R, Peak-Chew SY, Sade RS, Vallis Y, McMahon HT. The acetyltransferase activity of the bacterial toxin YopJ of Yersinia is activated by eukaryotic host cell inositol hexakisphosphate. J Biol Chem. 2010;285(26):19927-34. Epub 2010/05/01. doi: 10.1074/jbc.M110.126581. PubMed PMID: 20430892; PMCID: PMC2888404.

16. Philip NH, Brodsky IE. Cell death programs in Yersinia immunity and pathogenesis. Front Cell Infect Microbiol. 2012;2:149. Epub 2012/12/12. doi: 10.3389/fcimb.2012.00149. PubMed PMID: 23226685; PMCID: PMC3510641.

17. Zheng Y, Lilo S, Mena P, Bliska JB. YopJ-induced caspase-1 activation in Yersinia-infected macrophages: independent of apoptosis, linked to necrosis, dispensable for innate host defense. PLoS One. 2012;7(4):e36019. Epub 2012/05/09. doi: 10.1371/journal.pone.0036019. PubMed PMID: 22563435; PMCID: PMC3338577.

18. Galyov EE, Hakansson S, Wolf-Watz H. Characterization of the operon encoding the YpkA Ser/Thr protein kinase and the YopJ protein of Yersinia pseudotuberculosis. J Bacteriol. 1994;176(15):4543-8. Epub 1994/08/01. doi: 10.1128/jb.176.15.4543-4548.1994. PubMed PMID: 8045884; PMCID: PMC196273.

19. Lemaitre N, Sebbane F, Long D, Hinnebusch BJ. Yersinia pestis YopJ suppresses tumor necrosis factor alpha induction and contributes to apoptosis of immune cells in the lymph node but is not required for virulence in a rat model of bubonic plague. Infect Immun. 2006;74(9):5126-31. Epub 2006/08/24. doi: 10.1128/IAI.00219-06. PubMed PMID: 16926404; PMCID: PMC1594864. 20. Monack DM, Mecsas J, Bouley D, Falkow S. Yersinia-induced apoptosis in vivo aids in the establishment of a systemic infection of mice. J Exp Med. 1998;188(11):2127-37. Epub 1998/12/08. doi: 10.1084/jem.188.11.2127. PubMed PMID: 9841926; PMCID: PMC2212385. 21. Straley SC, Bowmer WS. Virulence genes regulated at the transcriptional level by Ca2+ in Yersinia pestis include structural genes for outer membrane proteins. Infect Immun. 1986;51(2):445-54. Epub 1986/02/01. doi: 10.1128/IAI.51.2.445-454.1986. PubMed PMID: 3002984; PMCID: PMC262351.

22. Straley SC, Cibull ML. Differential clearance and host-pathogen interactions of YopE- and YopK- YopL- Yersinia pestis in BALB/c mice. Infect Immun. 1989;57(4):1200-10. Epub 1989/04/01. doi: 10.1128/IAI.57.4.1200-1210.1989. PubMed PMID: 2925246; PMCID: PMC313251.

23. Trulzsch K, Sporleder T, Igwe EI, Russmann H, Heesemann J. Contribution of the major secreted yops of Yersinia enterocolitica 0:8 to pathogenicity in the mouse infection model. Infect Immun. 2004;72(9):5227-34. Epub 2004/08/24. doi: 10.1128/IAI.72.9.5227-5234.2004. PubMed PMID: 15322017; PMCID: PMC517446. 
891

892

893

894

895

896

897

898

899

900

901

902

903

904

905

906

907

908

909

910

911

912

913

914

915

916

917

918

919

920

921

922

923

924

925

926

927

928

929

930

931

932

933

934

935

936

937

938

939

940
24. Brodsky IE, Medzhitov R. Reduced secretion of YopJ by Yersinia limits in vivo cell death but enhances bacterial virulence. PLoS Pathog. 2008;4(5):e1000067. Epub 2008/05/17. doi:

10.1371/journal.ppat.1000067. PubMed PMID: 18483548; PMCID: PMC2361194.

25. Zauberman A, Tidhar A, Levy Y, Bar-Haim E, Halperin G, Flashner Y, Cohen S, Shafferman A, Mamroud E. Yersinia pestis endowed with increased cytotoxicity is avirulent in a bubonic plague model and induces rapid protection against pneumonic plague. PLoS One. 2009;4(6):e5938. Epub 2009/06/17. doi: 10.1371/journal.pone.0005938. PubMed PMID: 19529770; PMCID: PMC2691952.

26. Zheng Y, Lilo S, Brodsky IE, Zhang Y, Medzhitov R, Marcu KB, Bliska JB. A Yersinia effector with enhanced inhibitory activity on the NF-kappaB pathway activates the NLRP3/ASC/caspase-1 inflammasome in macrophages. PLoS Pathog. 2011;7(4):e1002026. Epub 2011/05/03. doi: 10.1371/journal.ppat.1002026. PubMed PMID: 21533069 ; PMCID: PMC3080847.

27. Stavrinides J, McCann HC, Guttman DS. Host-pathogen interplay and the evolution of bacterial effectors. Cell Microbiol. 2008;10(2):285-92. Epub 2007/11/24. doi: 10.1111/j.14625822.2007.01078.x. PubMed PMID: 18034865.

28. Terauchi R, Yoshida K. Towards population genomics of effector-effector target interactions. New Phytol. 2010;187(4):929-39. Epub 2010/08/17. doi: 10.1111/j.1469-8137.2010.03408.x. PubMed PMID: 20707855.

29. Yang Z, Rannala B. Molecular phylogenetics: principles and practice. Nat Rev Genet. 2012;13(5):303-14. Epub 2012/03/30. doi: 10.1038/nrg3186. PubMed PMID: 22456349.

30. Borges V, Nunes A, Ferreira R, Borrego MJ, Gomes JP. Directional evolution of Chlamydia trachomatis towards niche-specific adaptation. J Bacteriol. 2012;194(22):6143-53. Epub 2012/09/11. doi: 10.1128/JB.01291-12. PubMed PMID: 22961851; PMCID: PMC3486361. 31. Ma W, Dong FF, Stavrinides J, Guttman DS. Type III effector diversification via both pathoadaptation and horizontal transfer in response to a coevolutionary arms race. PLoS Genet. 2006;2(12):e209. Epub 2006/12/30. doi: 10.1371/journal.pgen.0020209. PubMed PMID: 17194219; PMCID: PMC1713259.

32. Chain PS, Carniel E, Larimer FW, Lamerdin J, Stoutland PO, Regala WM, Georgescu AM, Vergez LM, Land ML, Motin VL, Brubaker RR, Fowler J, Hinnebusch J, Marceau M, Medigue C, Simonet M, Chenal-Francisque V, Souza B, Dacheux D, Elliott JM, Derbise A, Hauser LJ, Garcia E. Insights into the evolution of Yersinia pestis through whole-genome comparison with Yersinia pseudotuberculosis. Proc Natl Acad Sci U S A. 2004;101(38):13826-31. Epub 2004/09/11. doi: 10.1073/pnas.0404012101. PubMed PMID: 15358858; PMCID: PMC518763.

33. Sun J. Pathogenic Bacterial Proteins and their Anti-Inflammatory Effects in the Eukaryotic Host. Antiinflamm Antiallergy Agents Med Chem. 2009;8(3):214-27. Epub 2010/01/22. doi: 10.2174/187152309789151986. PubMed PMID: 20090866; PMCID: PMC2808140.

34. Nielsen R, Yang Z. Likelihood models for detecting positively selected amino acid sites and applications to the HIV-1 envelope gene. Genetics. 1998;148(3):929-36. Epub 1998/04/16. PubMed PMID: 9539414; PMCID: PMC1460041.

35. Yang Z, Swanson WJ, Vacquier VD. Maximum-likelihood analysis of molecular adaptation in abalone sperm lysin reveals variable selective pressures among lineages and sites. Mol Biol Evol. 2000;17(10):1446-55. Epub 2000/10/06. doi: 10.1093/oxfordjournals.molbev.a026245. PubMed PMID: 11018152.

36. Barnes PD, Bergman MA, Mecsas J, Isberg RR. Yersinia pseudotuberculosis disseminates directly from a replicating bacterial pool in the intestine. J Exp Med. 2006;203(6):1591-601. Epub 2006/06/07. doi: 10.1084/jem.20060905. PubMed PMID: 16754724; PMCID: PMC2118325.

37. Zhang Y, Ting AT, Marcu KB, Bliska JB. Inhibition of MAPK and NF-kappa B pathways is necessary for rapid apoptosis in macrophages infected with Yersinia. J Immunol. 2005;174(12):7939-49. Epub 2005/06/10. doi: 10.4049/jimmunol.174.12.7939. PubMed PMID: 15944300. 
38. Boland A, Cornelis GR. Role of YopP in suppression of tumor necrosis factor alpha release by macrophages during Yersinia infection. Infect Immun. 1998;66(5):1878-84. Epub 1998/05/09. doi: 10.1128/IAI.66.5.1878-1884.1998. PubMed PMID: 9573064; PMCID: PMC108138.

39. Palmer LE, Hobbie S, Galan JE, Bliska JB. YopJ of Yersinia pseudotuberculosis is required for the inhibition of macrophage TNF-alpha production and downregulation of the MAP kinases p38 and JNK. Mol Microbiol. 1998;27(5):953-65. Epub 1998/04/16. doi: 10.1046/j.13652958.1998.00740.x. PubMed PMID: 9535085.

40. Schesser K, Spiik AK, Dukuzumuremyi JM, Neurath MF, Pettersson S, Wolf-Watz H. The yopJ locus is required for Yersinia-mediated inhibition of NF-kappaB activation and cytokine expression: YopJ contains a eukaryotic SH2-like domain that is essential for its repressive activity. Mol Microbiol. 1998;28(6):1067-79. Epub 1998/07/29. doi: 10.1046/j.1365-2958.1998.00851.x. PubMed PMID: 9680199.

41. Ruckdeschel K, Harb S, Roggenkamp A, Hornef M, Zumbihl R, Kohler S, Heesemann J, Rouot B. Yersinia enterocolitica impairs activation of transcription factor NF-kappaB: involvement in the induction of programmed cell death and in the suppression of the macrophage tumor necrosis factor alpha production. J Exp Med. 1998;187(7):1069-79. Epub 1998/05/16. doi: 10.1084/jem.187.7.1069. PubMed PMID: 9529323; PMCID: PMC2212204.

42. Inoue S, Sato T, Suzuki-Utsunomiya K, Komori Y, Hozumi K, Chiba T, Yahata T, Nakai K, Inokuchi S. Sepsis-induced hypercytokinemia and lymphocyte apoptosis in aging-accelerated Klotho knockout mice. Shock. 2013;39(3):311-6. Epub 2013/02/01. doi:

10.1097/SHK.0b013e3182845445. PubMed PMID: 23364432.

43. Teijaro JR, Walsh KB, Cahalan S, Fremgen DM, Roberts E, Scott F, Martinborough E, Peach R, Oldstone MB, Rosen $\mathrm{H}$. Endothelial cells are central orchestrators of cytokine amplification during influenza virus infection. Cell. 2011;146(6):980-91. Epub 2011/09/20. doi: 10.1016/j.cell.2011.08.015. PubMed PMID: 21925319; PMCID: PMC3176439.

44. Ulloa L, Tracey KJ. The "cytokine profile": a code for sepsis. Trends Mol Med. 2005;11(2):5663. Epub 2005/02/08. doi: 10.1016/j.molmed.2004.12.007. Pub Med PMID: 15694867.

45. van Rooijen N, van Kesteren-Hendrikx E. "In vivo" depletion of macrophages by liposomemediated "suicide". Methods Enzymol. 2003;373:3-16. Epub 2004/01/13. doi: 10.1016/s00766879(03)73001-8. PubMed PMID: 14714393.

46. Eichhorst ST, Krueger A, Muerkoster S, Fas SC, Golks A, Gruetzner U, Schubert L, Opelz C, Bilzer M, Gerbes AL, Krammer PH. Suramin inhibits death receptor-induced apoptosis in vitro and fulminant apoptotic liver damage in mice. Nat Med. 2004;10(6):602-9. Epub 2004/05/18. doi: 10.1038/nm1049. PubMed PMID: 15146177.

47. Goto T, Takeuchi S, Miura K, Ohshima S, Mikami K, Yoneyama K, Sato M, Shibuya T, Watanabe D, Kataoka E, Segawa D, Endo A, Sato W, Yoshino R, Watanabe S. Suramin prevents fulminant hepatic failure resulting in reduction of lethality through the suppression of NF-kappaB activity. Cytokine. 2006;33(1):28-35. Epub 2006/01/18. doi: 10.1016/j.cyto.2005.11.012. PubMed PMID: 16413198.

48. Ruckdeschel K, Richter K, Mannel 0, Heesemann J. Arginine-143 of Yersinia enterocolitica YopP crucially determines isotype-related NF-kappaB suppression and apoptosis induction in macrophages. Infect Immun. 2001;69(12):7652-62. Epub 2001/11/14. doi: 10.1128/IAI.69.12.7652-7662.2001. PubMed PMID: 11705945; PMCID: PMC98859.

49. Zauberman A, Cohen S, Mamroud E, Flashner Y, Tidhar A, Ber R, Elhanany E, Shafferman A, Velan B. Interaction of Yersinia pestis with macrophages: limitations in YopJ-dependent apoptosis. Infect Immun. 2006;74(6):3239-50. Epub 2006/05/23. doi: 10.1128/IAI.00097-06. PubMed PMID: 16714551; PMCID: PMC1479247.

50. Bolin I, Norlander L, Wolf-Watz H. Temperature-inducible outer membrane protein of Yersinia pseudotuberculosis and Yersinia enterocolitica is associated with the virulence plasmid. 
Infect Immun. 1982;37(2):506-12. Epub 1982/08/01. doi: 10.1128/IAI.37.2.506-512.1982. PubMed PMID: 6749681; PMCID: PMC347563.

51. Portnoy DA, Wolf-Watz H, Bolin I, Beeder AB, Falkow S. Characterization of common virulence plasmids in Yersinia species and their role in the expression of outer membrane proteins. Infect Immun. 1984;43(1):108-14. Epub 1984/01/01. doi: 10.1128/IAI.43.1.108-114.1984. PubMed PMID: 6317562; PMCID: PMC263395.

52. Easterday WR, Kausrud KL, Star B, Heier L, Haley BJ, Ageyev V, Colwell RR, Stenseth NC. An additional step in the transmission of Yersinia pestis? ISME J. 2012;6(2):231-6. Epub 2011/08/13. doi: 10.1038/ismej.2011.105. PubMed PMID: 21833036; PMCID: PMC3260498.

53. Orning P, Weng D, Starheim K, Ratner D, Best Z, Lee B, Brooks A, Xia S, Wu H, Kelliher MA, Berger SB, Gough PJ, Bertin J, Proulx MM, Goguen JD, Kayagaki N, Fitzgerald KA, Lien E. Pathogen blockade of TAK1 triggers caspase-8-dependent cleavage of gasdermin D and cell death. Science. 2018;362(6418):1064-9. Epub 2018/10/27. doi: 10.1126/science.aau2818. PubMed PMID: 30361383; PMCID: PMC6522129.

54. Paquette N, Conlon J, Sweet C, Rus F, Wilson L, Pereira A, Rosadini CV, Goutagny N, Weber AN, Lane WS, Shaffer SA, Maniatis S, Fitzgerald KA, Stuart L, Silverman N. Serine/threonine acetylation of TGFbeta-activated kinase (TAK1) by Yersinia pestis YopJ inhibits innate immune signaling. Proc Natl Acad Sci U S A. 2012;109(31):12710-5. Epub 2012/07/18. doi: 10.1073/pnas.1008203109. PubMed PMID: 22802624; PMCID: PMC3411953.

55. Philip NH, Dillon CP, Snyder AG, Fitzgerald P, Wynosky-Dolfi MA, Zwack EE, Hu B, Fitzgerald L, Mauldin EA, Copenhaver AM, Shin S, Wei L, Parker M, Zhang J, Oberst A, Green DR, Brodsky IE. Caspase-8 mediates caspase-1 processing and innate immune defense in response to bacterial blockade of NF-kappaB and MAPK signaling. Proc Natl Acad Sci U S A. 2014;111(20):7385-90. Epub 2014/05/07. doi: 10.1073/pnas.1403252111. Pub Med PMID: 24799700; PMCID: PMC4034241.

1014

1015

1016 Green DR, Poltorak A. Caspase-8 induces cleavage of gasdermin D to elicit pyroptosis during Yersinia infection. Proc Natl Acad Sci U S A. 2018;115(46):E10888-E97. Epub 2018/11/02. doi: 10.1073/pnas.1809548115. PubMed PMID: 30381458; PMCID: PMC6243247.

57. Peterson LW, Philip NH, Dillon CP, Bertin J, Gough PJ, Green DR, Brodsky IE. Cell-Extrinsic TNF Collaborates with TRIF Signaling To Promote Yersinia-Induced Apoptosis. J Immunol. 2016;197(10):4110-7. Epub 2016/10/14. doi: 10.4049/jimmunol.1601294. Pub Med PMID: 27733552; PMCID: PMC5123756.

58. Weng D, Marty-Roix R, Ganesan S, Proulx MK, Vladimer GI, Kaiser WJ, Mocarski ES, Pouliot K, Chan FK, Kelliher MA, Harris PA, Bertin J, Gough PJ, Shayakhmetov DM, Goguen JD, Fitzgerald KA, Silverman N, Lien E. Caspase-8 and RIP kinases regulate bacteria-induced innate immune responses and cell death. Proc Natl Acad Sci U S A. 2014;111(20):7391-6. Epub 2014/05/07. doi: 10.1073/pnas.1403477111. PubMed PMID: 24799678; PMCID: PMC4034196.

59. Bergman MA, Loomis WP, Mecsas J, Starnbach MN, Isberg RR. CD8(+) T cells restrict Yersinia pseudotuberculosis infection: bypass of anti-phagocytosis by targeting antigen-presenting cells. PLoS Pathog. 2009;5(9):e1000573. Epub 2009/09/05. doi: 10.1371/journal.ppat.1000573. PubMed PMID: 19730693; PMCID: PMC2731216.

60. Meinzer U, Barreau F, Esmiol-Welterlin S, Jung C, Villard C, Leger T, Ben-Mkaddem S, Berrebi D, Dussaillant M, Alnabhani Z, Roy M, Bonacorsi S, Wolf-Watz H, Perroy J, Ollendorff V, Hugot JP. Yersinia pseudotuberculosis effector YopJ subverts the Nod2/RICK/TAK1 pathway and activates caspase-1 to induce intestinal barrier dysfunction. Cell Host Microbe. 2012;11(4):337-51. Epub 2012/04/24. doi: 10.1016/j.chom.2012.02.009. PubMed PMID: 22520462.

61. Arifuzzaman M, Ang WXG, Choi HW, Nilles ML, St John AL, Abraham SN. Necroptosis of infiltrated macrophages drives Yersinia pestis dispersal within buboes. JCI Insight. 2018;3(18). Epub 2018/09/21. doi: 10.1172/jci.insight.122188. PubMed PMID: 30232285; PMCID: PMC6237236. 
1040

1041

1042

1043

1044

1045

1046

1047

1048

1049

1050

1051

1052

1053

1054

1055

1056

1057

1058

1059

1060

1061

1062

1063

1064

1065

1066

1067

1068

1069

1070

1071

1072

1073

1074

1075

1076

1077

1078

1079

1080

1081

1082

1083

1084

1085

1086

1087

1088

1089

62. Dewoody R, Merritt PM, Houppert AS, Marketon MM. YopK regulates the Yersinia pestis type III secretion system from within host cells. Mol Microbiol. 2011;79(6):1445-61. Epub 2011/01/06. doi: 10.1111/j.1365-2958.2011.07534.x. PubMed PMID: 21205017; PMCID: PMC3210821.

63. Dewoody R, Merritt PM, Marketon MM. YopK controls both rate and fidelity of Yop translocation. Mol Microbiol. 2013;87(2):301-17. Epub 2012/12/05. doi: 10.1111/mmi.12099. PubMed PMID: 23205707; PMCID: PMC3545096.

64. Zhuang S, Lu B, Daubert RA, Chavin KD, Wang L, Schnellmann RG. Suramin promotes recovery from renal ischemia/reperfusion injury in mice. Kidney Int. 2009;75(3):304-11. Epub 2008/10/10. doi: 10.1038/ki.2008.506. PubMed PMID: 18843260.

65. Dupre TV, Doll MA, Shah PP, Sharp CN, Kiefer A, Scherzer MT, Saurabh K, Saforo D, Siow D, Casson L, Arteel GE, Jenson AB, Megyesi J, Schnellmann RG, Beverly LJ, Siskind LJ. Suramin protects from cisplatin-induced acute kidney injury. Am J Physiol Renal Physiol. 2016;310(3):F248-58. Epub 2015/12/15. doi: 10.1152/ajprenal.00433.2015. PubMed PMID: 26661653; PMCID: PMC4877945. 66. Wiedemar N, Hauser DA, Maser P. 100 Years of Suramin. Antimicrob Agents Chemother. 2020;64(3). Epub 2019/12/18. doi: 10.1128/AAC.01168-19. PubMed PMID: 31844000; PMCID: PMC7038244.

67. Vandenabeele P, Vanden Berghe T, Festjens N. Caspase inhibitors promote alternative cell death pathways. Sci STKE. 2006;2006(358):pe44. Epub 2006/10/26. doi: 10.1126/stke.3582006pe44. PubMed PMID: 17062895.

68. Lewis JD, Lee A, Ma W, Zhou H, Guttman DS, Desveaux D. The YopJ superfamily in plantassociated bacteria. Mol Plant Pathol. 2011;12(9):928-37. Epub 2011/07/06. doi: 10.1111/j.13643703.2011.00719.x. PubMed PMID: 21726386; PMCID: PMC6640427.

69. Fehr D, Casanova C, Liverman A, Blazkova H, Orth K, Dobbelaere D, Frey J, Burr SE. AopP, a type III effector protein of Aeromonas salmonicida, inhibits the NF-kappaB signalling pathway. Microbiology. 2006;152(Pt 9):2809-18. Epub 2006/09/02. doi: 10.1099/mic.0.28889-0. PubMed PMID: 16946275.

70. Trosky JE, Mukherjee S, Burdette DL, Roberts M, McCarter L, Siegel RM, Orth K. Inhibition of MAPK signaling pathways by VopA from Vibrio parahaemolyticus. J Biol Chem.

2004;279(50):51953-7. Epub 2004/10/02. doi: 10.1074/jbc.M407001200. PubMed PMID: 15459200 .

71. Alsmark CM, Frank AC, Karlberg EO, Legault BA, Ardell DH, Canback B, Eriksson AS, Naslund AK, Handley SA, Huvet M, La Scola B, Holmberg M, Andersson SG. The louse-borne human pathogen Bartonella quintana is a genomic derivative of the zoonotic agent Bartonella henselae. Proc Natl Acad Sci U S A. 2004;101(26):9716-21. Epub 2004/06/24. doi: 10.1073/pnas.0305659101.

PubMed PMID: 15210978; PMCID: PMC470741.

72. Hardt WD, Galan JE. A secreted Salmonella protein with homology to an avirulence determinant of plant pathogenic bacteria. Proc Natl Acad Sci U S A. 1997;94(18):9887-92. Epub 1997/09/02. doi: 10.1073/pnas.94.18.9887. Pub Med PMID: 9275221; PMCID: PMC23287.

73. Collier-Hyams LS, Zeng H, Sun J, Tomlinson AD, Bao ZQ, Chen H, Madara JL, Orth K, Neish AS. Cutting edge: Salmonella AvrA effector inhibits the key proinflammatory, anti-apoptotic NF-kappa B pathway. J Immunol. 2002;169(6):2846-50. Epub 2002/09/10. doi: 10.4049/jimmunol.169.6.2846. PubMed PMID: 12218096.

74. Jones RM, Wu H, Wentworth C, Luo L, Collier-Hyams L, Neish AS. Salmonella AvrA Coordinates Suppression of Host Immune and Apoptotic Defenses via JNK Pathway Blockade. Cell Host Microbe. 2008;3(4):233-44. Epub 2008/04/15. doi: 10.1016/j.chom.2008.02.016. PubMed PMID: 18407067.

75. Liu X, Lu R, Xia Y, Wu S, Sun J. Eukaryotic signaling pathways targeted by Salmonella effector protein AvrA in intestinal infection in vivo. BMC Microbiol. 2010;10:326. Epub 2010/12/25. doi: 10.1186/1471-2180-10-326. PubMed PMID: 21182782; PMCID: PMC3027599. 
1090

1091

1092

1093

1094

1095

1096

1097

1098

1099

1100

1101

1102

1103

1104

1105

1106

1107

1108

1109

1110

1111

1112

1113

1114

1115

1116

1117

1118

1119

1120

1121

1122

1123

1124

1125

1126

1127

1128

1129

1130

1131

1132

1133

1134

1135

1136

1137

1138

1139

76. Schesser K, Dukuzumuremyi JM, Cilio C, Borg S, Wallis TS, Pettersson S, Galyov EE. The Salmonella YopJ-homologue AvrA does not possess YopJ-like activity. Microb Pathog. 2000;28(2):59-70. Epub 2000/01/25. doi: 10.1006/mpat.1999.0324. PubMed PMID: 10644492. 77. Du F, Galan JE. Selective inhibition of type III secretion activated signaling by the Salmonella effector AvrA. PLoS Pathog. 2009;5(9):e1000595. Epub 2009/09/26. doi: 10.1371/journal.ppat.1000595. PubMed PMID: 19779561; PMCID: PMC2742890.

78. Coll NS, Epple P, Dangl JL. Programmed cell death in the plant immune system. Cell Death Differ. 2011;18(8):1247-56. Epub 2011/04/09. doi: 10.1038/cdd.2011.37. Pub Med PMID: 21475301; PMCID: PMC3172094.

79. Roden J, Eardley L, Hotson A, Cao Y, Mudgett MB. Characterization of the Xanthomonas AvrXv4 effector, a SUMO protease translocated into plant cells. Mol Plant Microbe Interact. 2004;17(6):633-43. Epub 2004/06/16. doi: 10.1094/MPMI.2004.17.6.633. PubMed PMID: 15195946.

80. Lee AH, Hurley B, Felsensteiner C, Yea C, Ckurshumova W, Bartetzko V, Wang PW, Quach V, Lewis JD, Liu YC, Bornke F, Angers S, Wilde A, Guttman DS, Desveaux D. A bacterial acetyltransferase destroys plant microtubule networks and blocks secretion. PLoS Pathog. 2012;8(2):e1002523. Epub 2012/02/10. doi: 10.1371/journal.ppat.1002523. Pub Med PMID: $22319451 ;$ PMCID: PMC3271077.

81. Sanabria NM, Huang JC, Dubery IA. Self/nonself perception in plants in innate immunity and defense. Self Nonself. 2010;1(1):40-54. Epub 2010/01/01. doi: 10.4161/self.1.1.10442. PubMed PMID: 21559176; PMCID: PMC3091600.

82. Prehna G, Ivanov MI, Bliska JB, Stebbins CE. Yersinia virulence depends on mimicry of host Rho-family nucleotide dissociation inhibitors. Cell. 2006;126(5):869-80. Epub 2006/09/09. doi: 10.1016/j.cell.2006.06.056. PubMed PMID: 16959567.

83. Gu J, Neary JL, Sanchez M, Yu J, Lilburn TG, Wang Y. Genome evolution and functional divergence in Yersinia. J Exp Zool B Mol Dev Evol. 2007;308(1):37-49. Epub 2006/07/14. doi: 10.1002/jez.b.21120. PubMed PMID: 16838303.

84. Cui Y, Yu C, Yan Y, Li D, Li Y, Jombart T, Weinert LA, Wang Z, Guo Z, Xu L, Zhang Y, Zheng H, Qin N, Xiao X, Wu M, Wang X, Zhou D, Qi Z, Du Z, Wu H, Yang X, Cao H, Wang H, Wang J, Yao S, Rakin A, Li Y, Falush D, Balloux F, Achtman M, Song Y, Wang J, Yang R. Historical variations in mutation rate in an epidemic pathogen, Yersinia pestis. Proc Natl Acad Sci U S A. 2013;110(2):577-82. Epub 2012/12/29. doi: 10.1073/pnas.1205750110. Pub Med PMID: 23271803; PMCID: PMC3545753. 85. Stenkova AM, Isaeva MP, Shubin FN, Rasskazov VA, Rakin AV. Trends of the major porin gene (ompF) evolution: insight from the genus Yersinia. PLoS One. 2011;6(5):e20546. Epub 2011/06/10. doi: 10.1371/journal.pone.0020546. PubMed PMID: 21655186; PMCID: PMC3105102.

86. Elde NC, Child SJ, Geballe AP, Malik HS. Protein kinase R reveals an evolutionary model for defeating viral mimicry. Nature. 2009;457(7228):485-9. Epub 2008/12/02. doi: 10.1038/nature07529. Pub Med PMID: 19043403; PMCID: PMC2629804.

87. Wiley DJ, Shrestha N, Yang J, Atis N, Dayton K, Schesser K. The activities of the Yersinia protein kinase A (YpkA) and outer protein J (YopJ) virulence factors converge on an elF2alpha kinase. J Biol Chem. 2009;284(37):24744-53. Epub 2009/06/26. doi: 10.1074/jbc.M109.010140. PubMed PMID: 19553678; PMCID: PMC2757178.

88. Bergman MA, Cummings LA, Alaniz RC, Mayeda L, Fellnerova I, Cookson BT. CD4+-T-cell responses generated during murine Salmonella enterica serovar Typhimurium infection are directed towards multiple epitopes within the natural antigen FliC. Infect Immun.

2005;73(11):7226-35. Epub 2005/10/22. doi: 10.1128/IAI.73.11.7226-7235.2005. PubMed PMID: $16239517 ;$ PMCID: PMC1273846.

89. Mecsas J, Bilis I, Falkow S. Identification of attenuated Yersinia pseudotuberculosis strains and characterization of an orogastric infection in BALB/c mice on day 5 postinfection by signature- 
1140 tagged mutagenesis. Infect Immun. 2001;69(5):2779-87. Epub 2001/04/09. doi:

1141 10.1128/IAI.67.5.2779-2787.2001. PubMed PMID: 11292689; PMCID: PMC98225.

1142 90. Fisher ML, Castillo C, Mecsas J. Intranasal inoculation of mice with Yersinia

1143 pseudotuberculosis causes a lethal lung infection that is dependent on Yersinia outer proteins and

1144 PhoP. Infect Immun. 2007;75(1):429-42. Epub 2006/11/01. doi: 10.1128/IAI.01287-06. PubMed

1145 PMID: 17074849; PMCID: PMC1828392.

1146 91. Van Rooijen N, Sanders A. Liposome mediated depletion of macrophages: mechanism of

1147 action, preparation of liposomes and applications. J Immunol Methods. 1994;174(1-2):83-93. Epub

1148 1994/09/14. doi: 10.1016/0022-1759(94)90012-4. PubMed PMID: 8083541.

1149 92. Schneider CA, Rasband WS, Eliceiri KW. NIH Image to ImageJ: 25 years of image analysis.

1150 Nat Methods. 2012;9(7):671-5. Epub 2012/08/30. doi: 10.1038/nmeth.2089. PubMed PMID:

1151 22930834; PMCID: PMC5554542. 
(A)

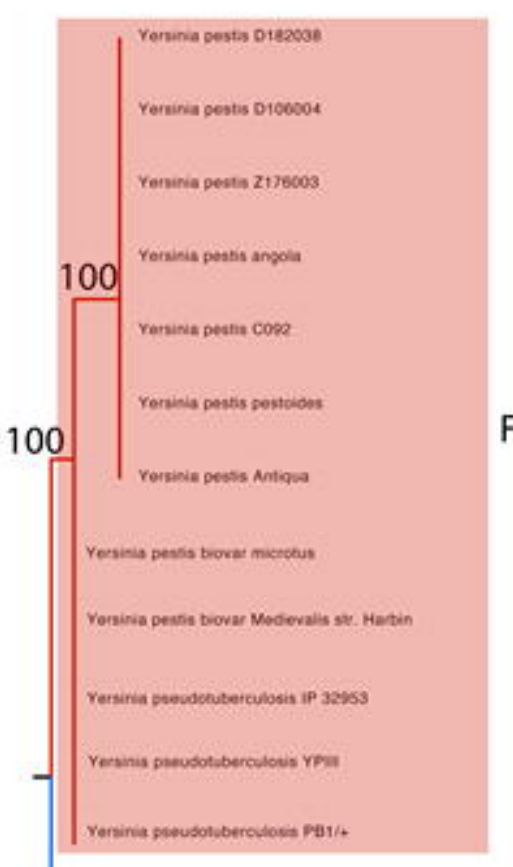

(B)

r.pentis o162038

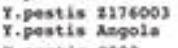
r. pestis cosiz r. pestis Antiqua

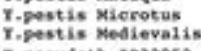
T.puesdotb IPJ2959 I. peresdotb PB1/+

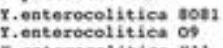

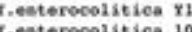
r.pentis Kis

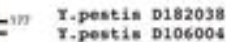
r.pestis: 2176003 r.pestis Angola r.pestis $\mathrm{COg} 2$ $x$.pestis Antiqua

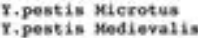
x. pseudotb trs295s x. pseudotb pat/\%

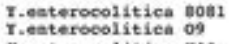
$x$,enterocolitica $\mathrm{xt}$ $x$,enterocolitica des x. pestis KIK

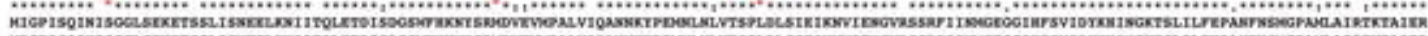

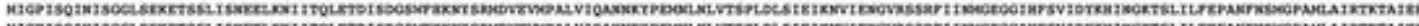
-

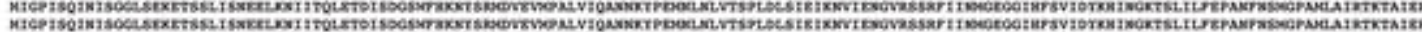

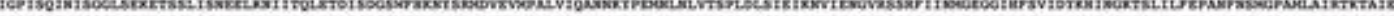

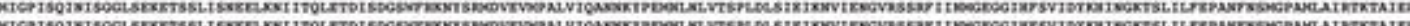

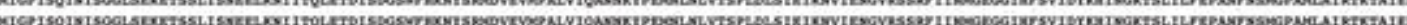

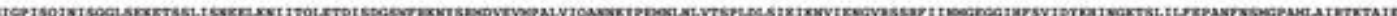

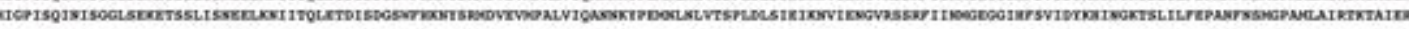

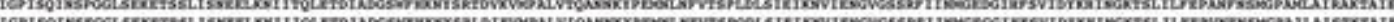

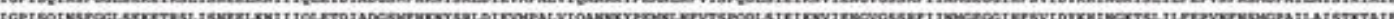
kteritots

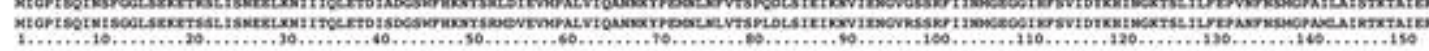

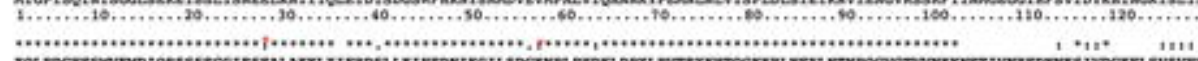

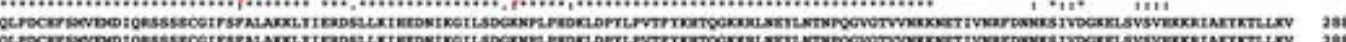
源 Gersar TPen C

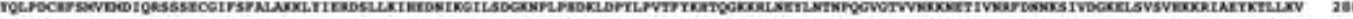

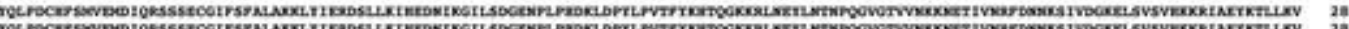

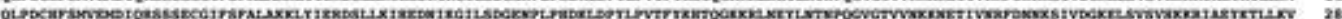

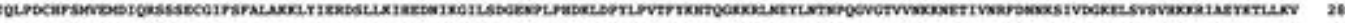

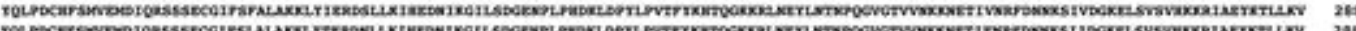
Gerscers

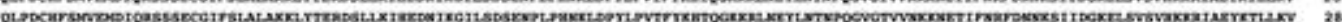

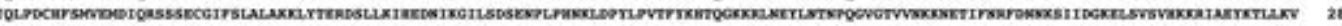

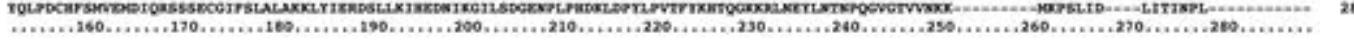

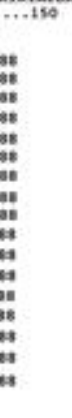


Figure 2.

A.

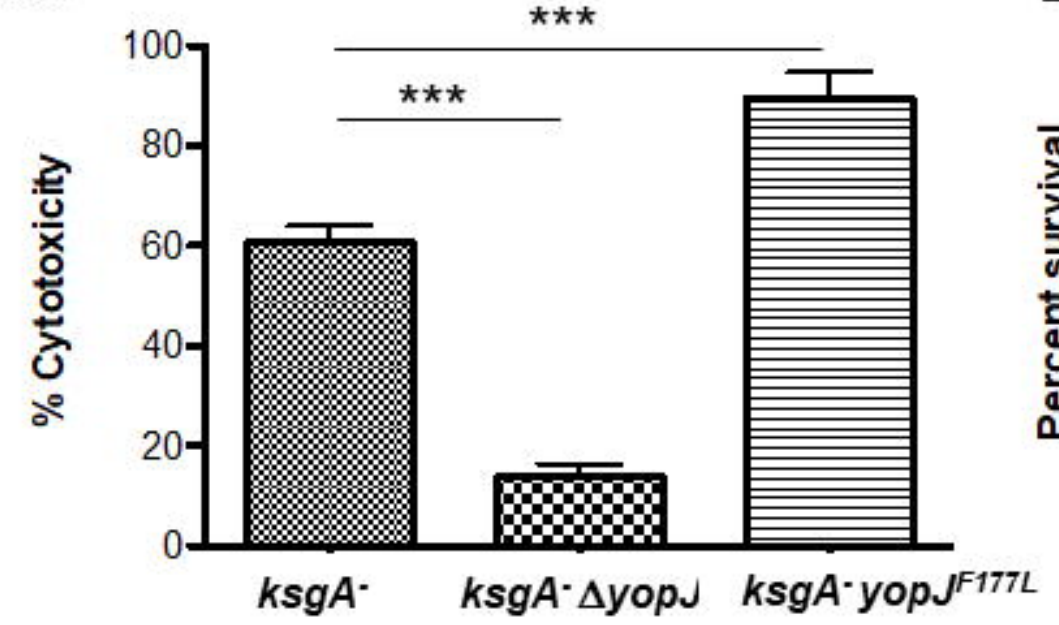

B.

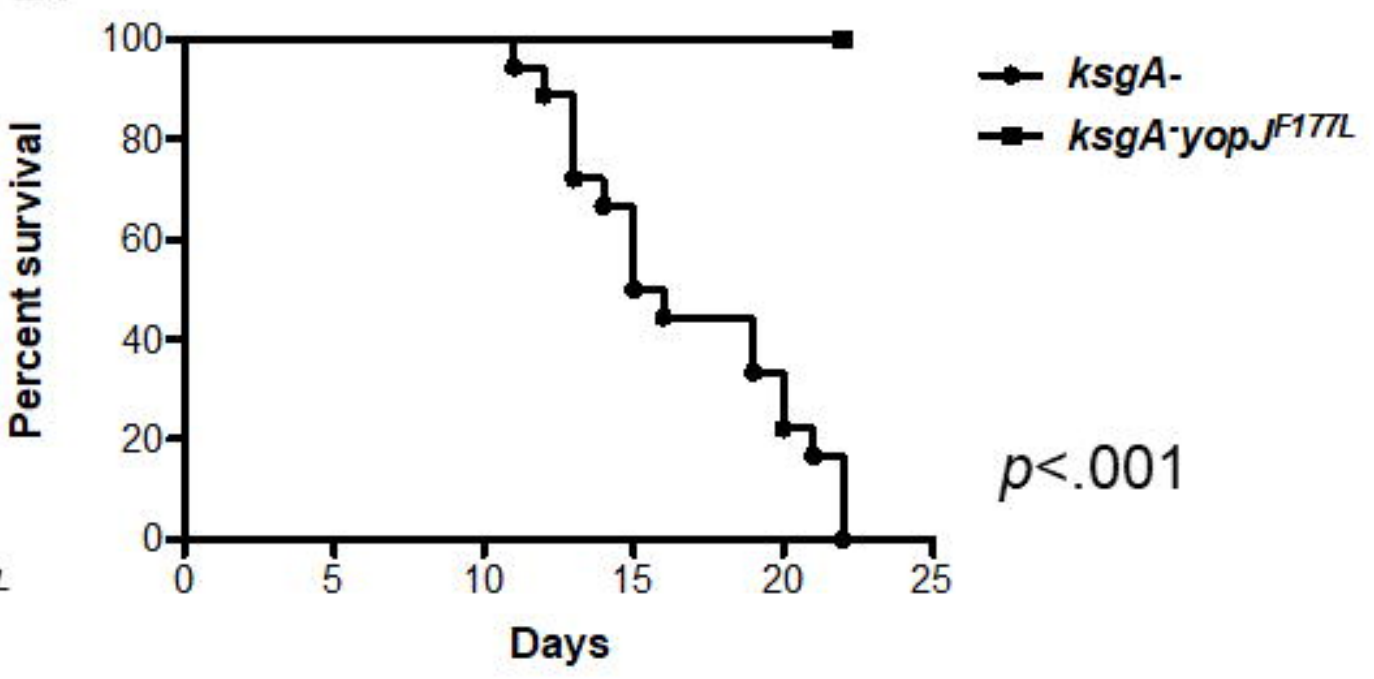


Figure 3.
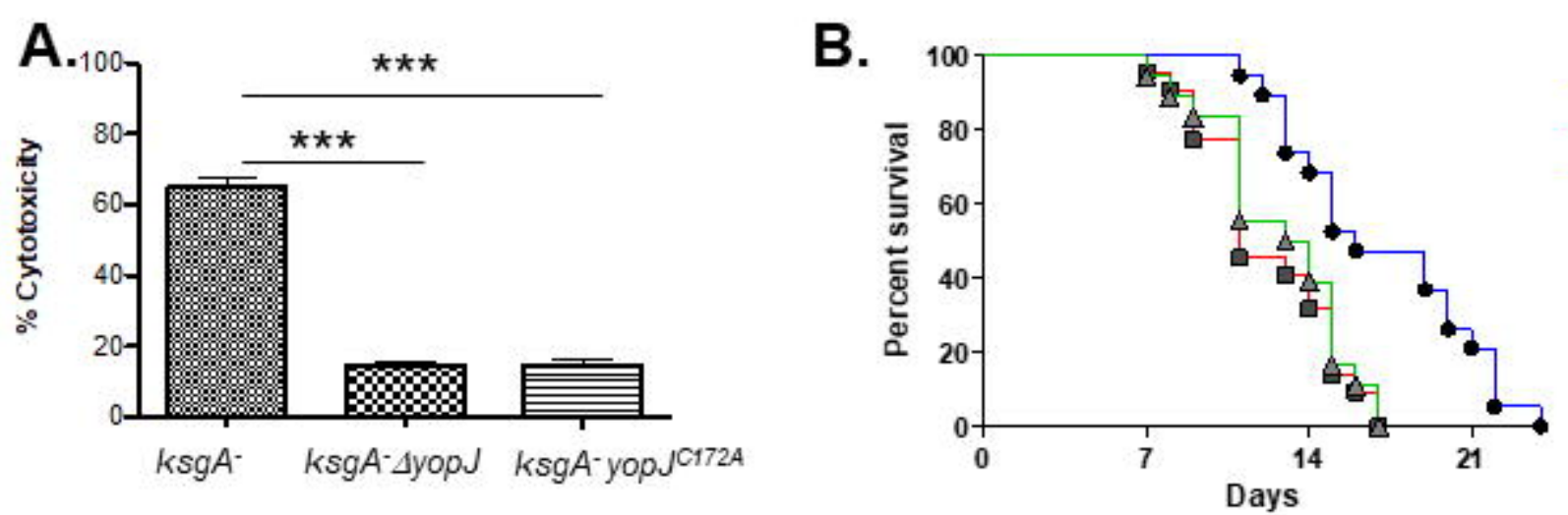

- $k s g A^{-}$

- ksga $\triangle$ yopl

$\triangle k_{s} g A^{-} y o J^{C 172 A}$

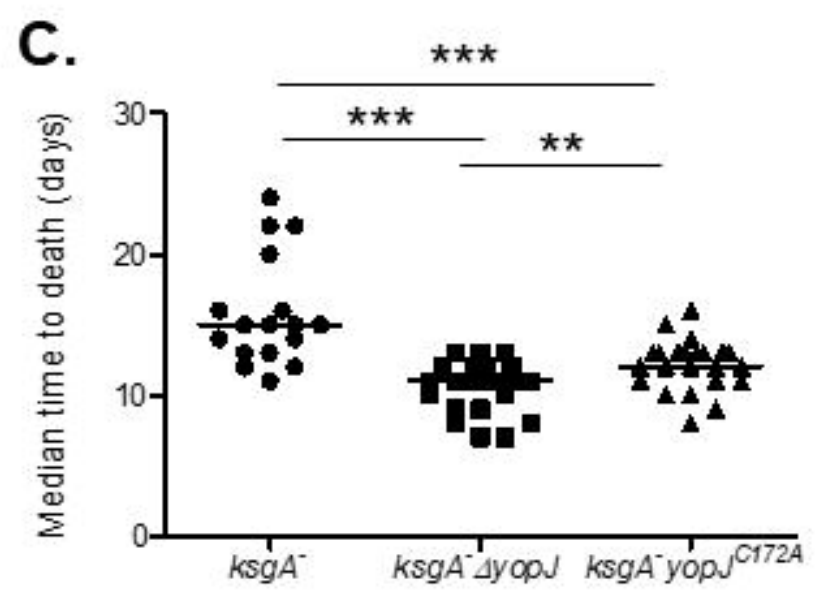


Figure 4.
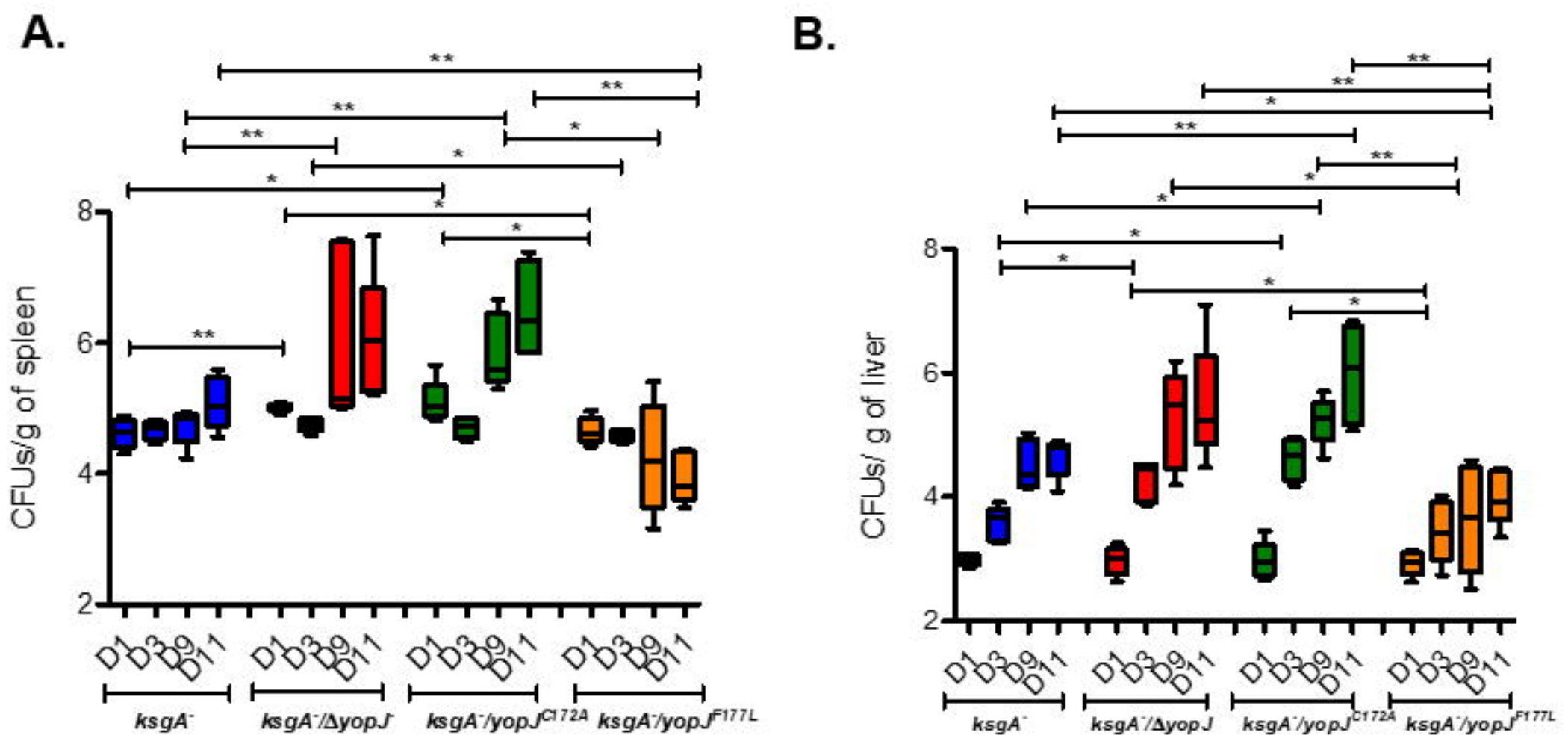
Figure 5.

A.

B.

Y. pstb

C. TUNEL Y. pstb DAPI
PBS

$k s g A^{-}$

$k s g A^{*}$ -

$k_{s g A^{-} \text {уор } J^{C 172 A} \quad \text { ksgA-yopj }}{ }^{F 177 L}$

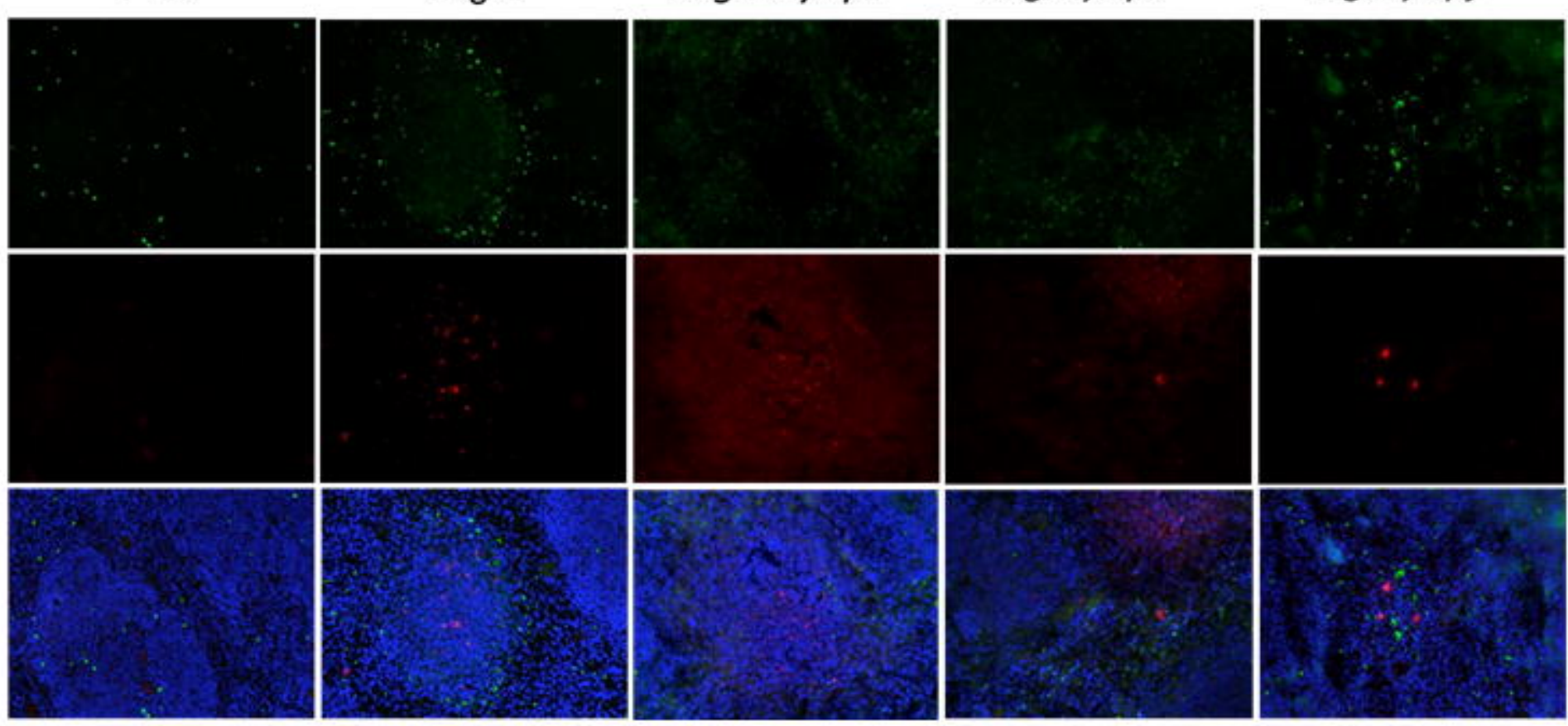

D.

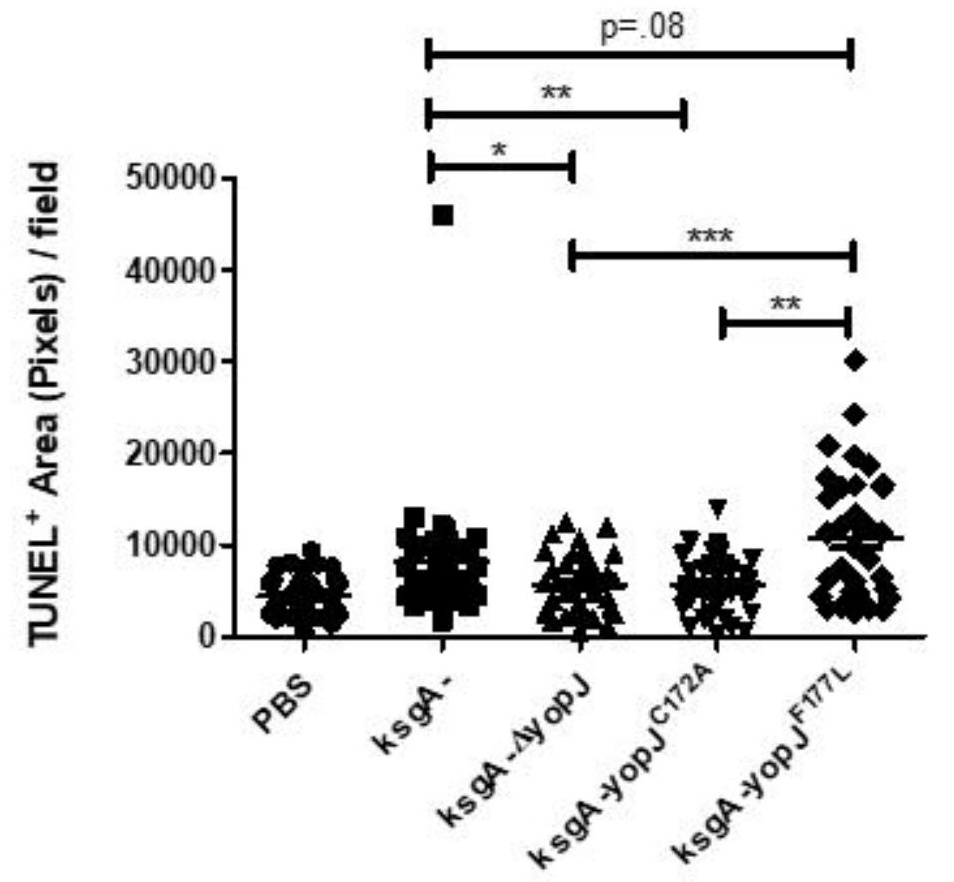


Figure 6.

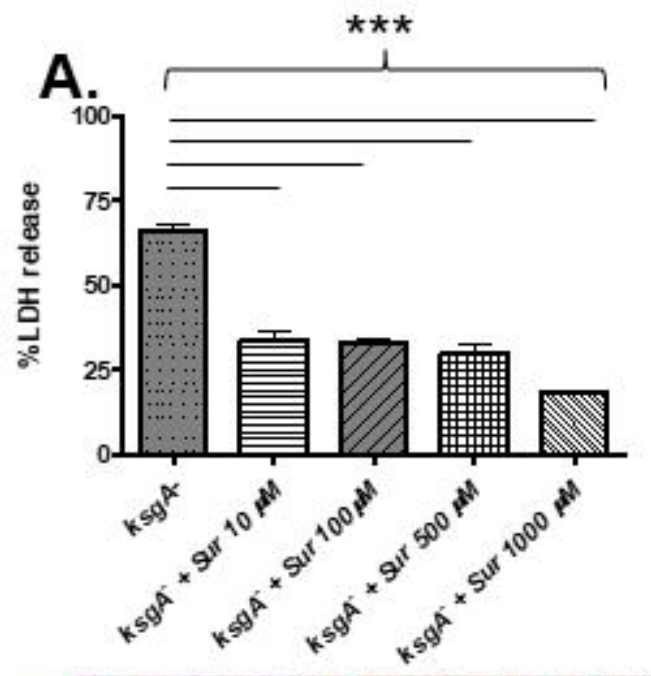

C. $k s g A+P B S$ 3DPI D $k s g A+$ suramin 3DPI

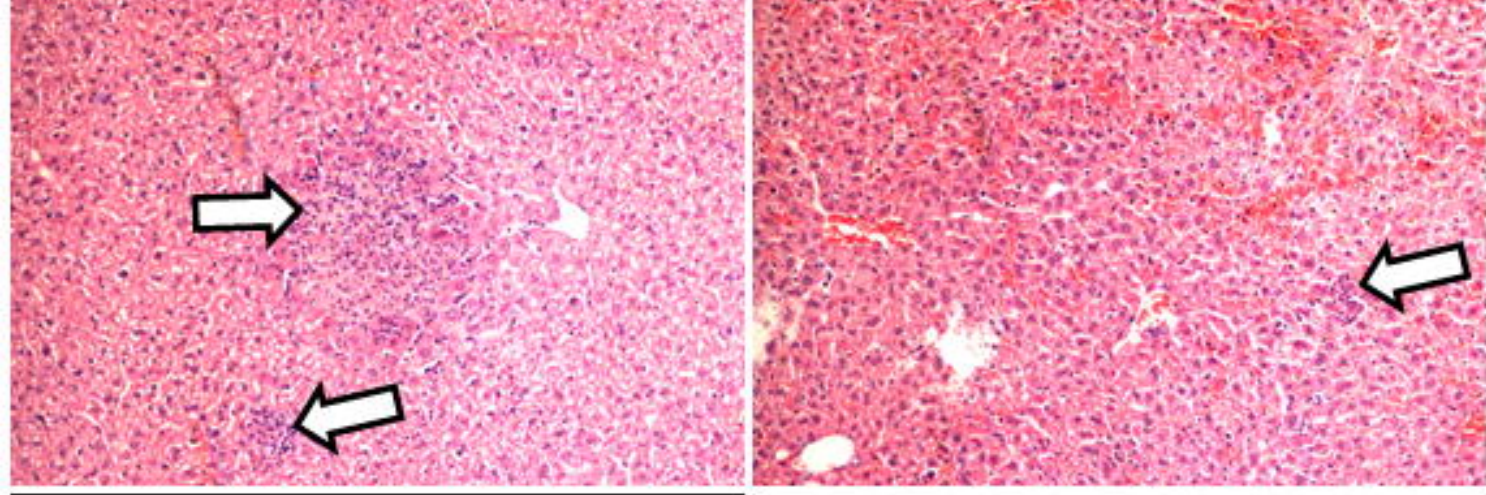

F. $k s g A^{-}+$PBS 3DPI

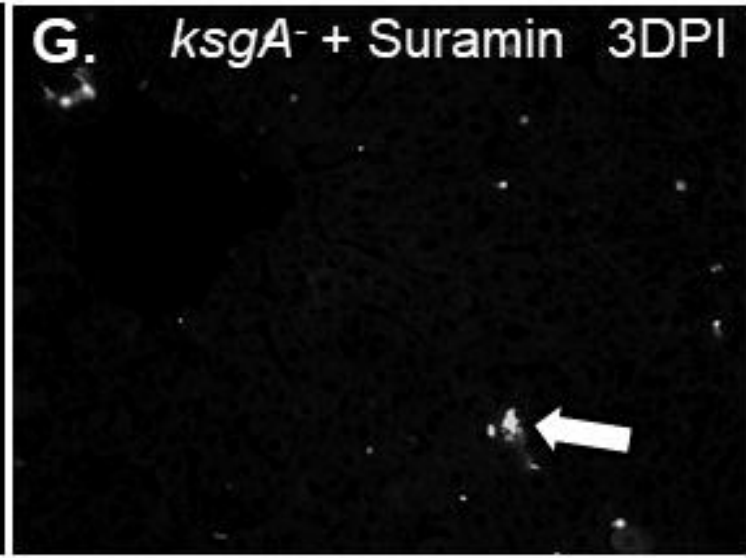

B.
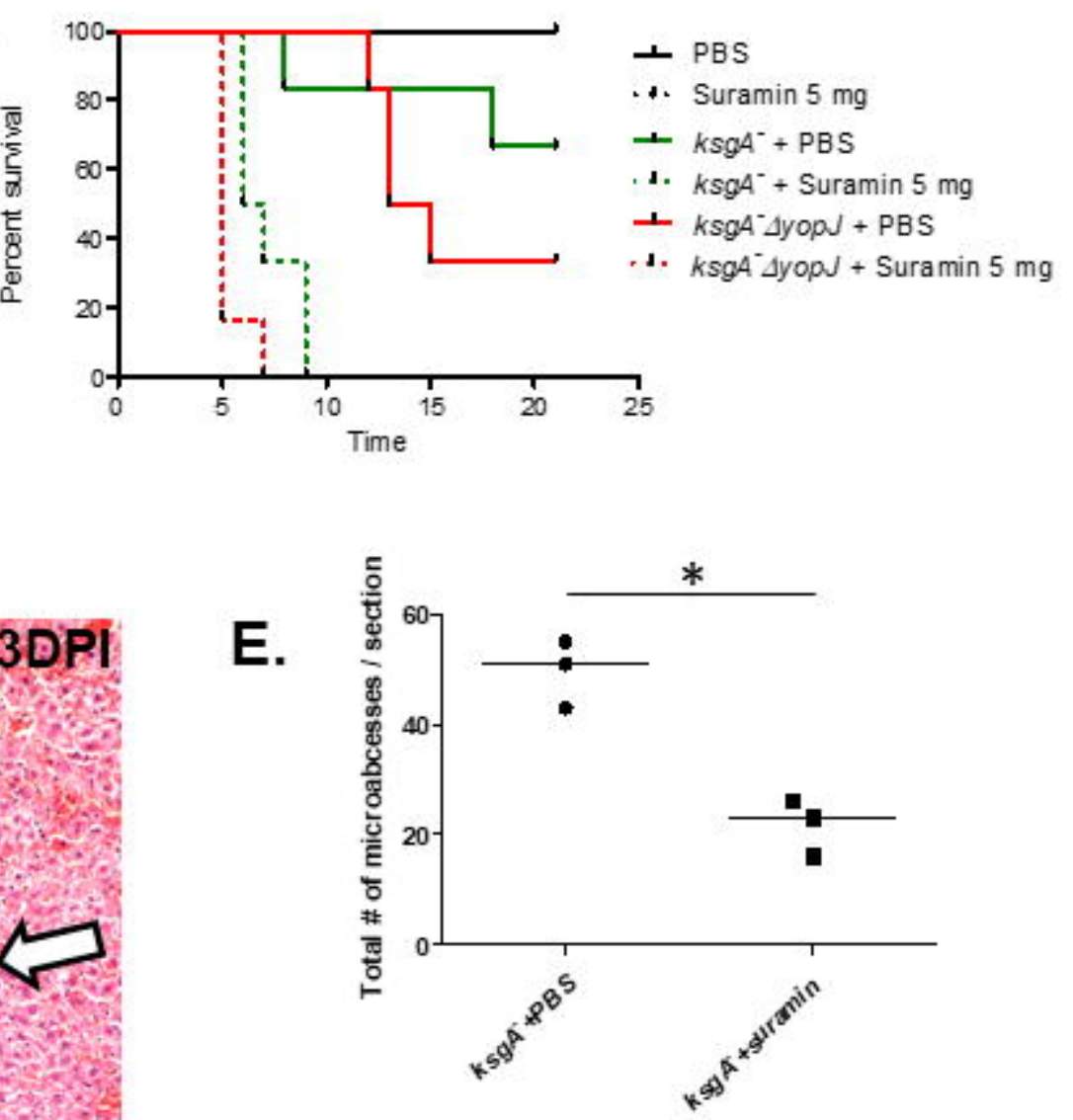

H.

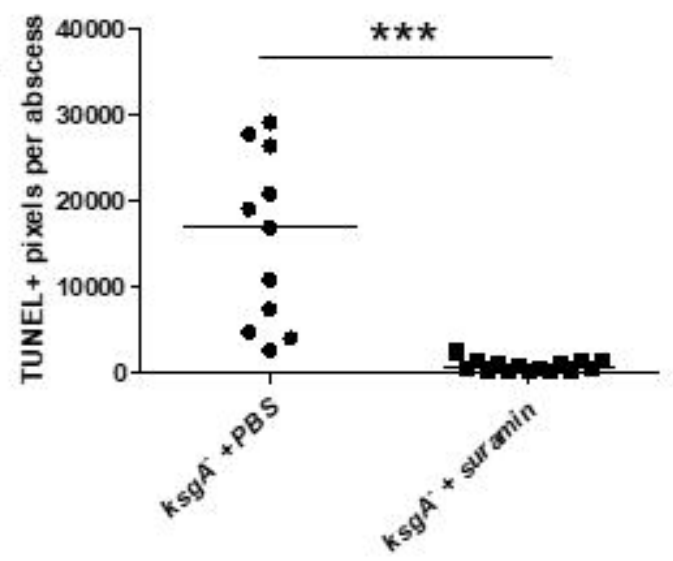


Figure 7.

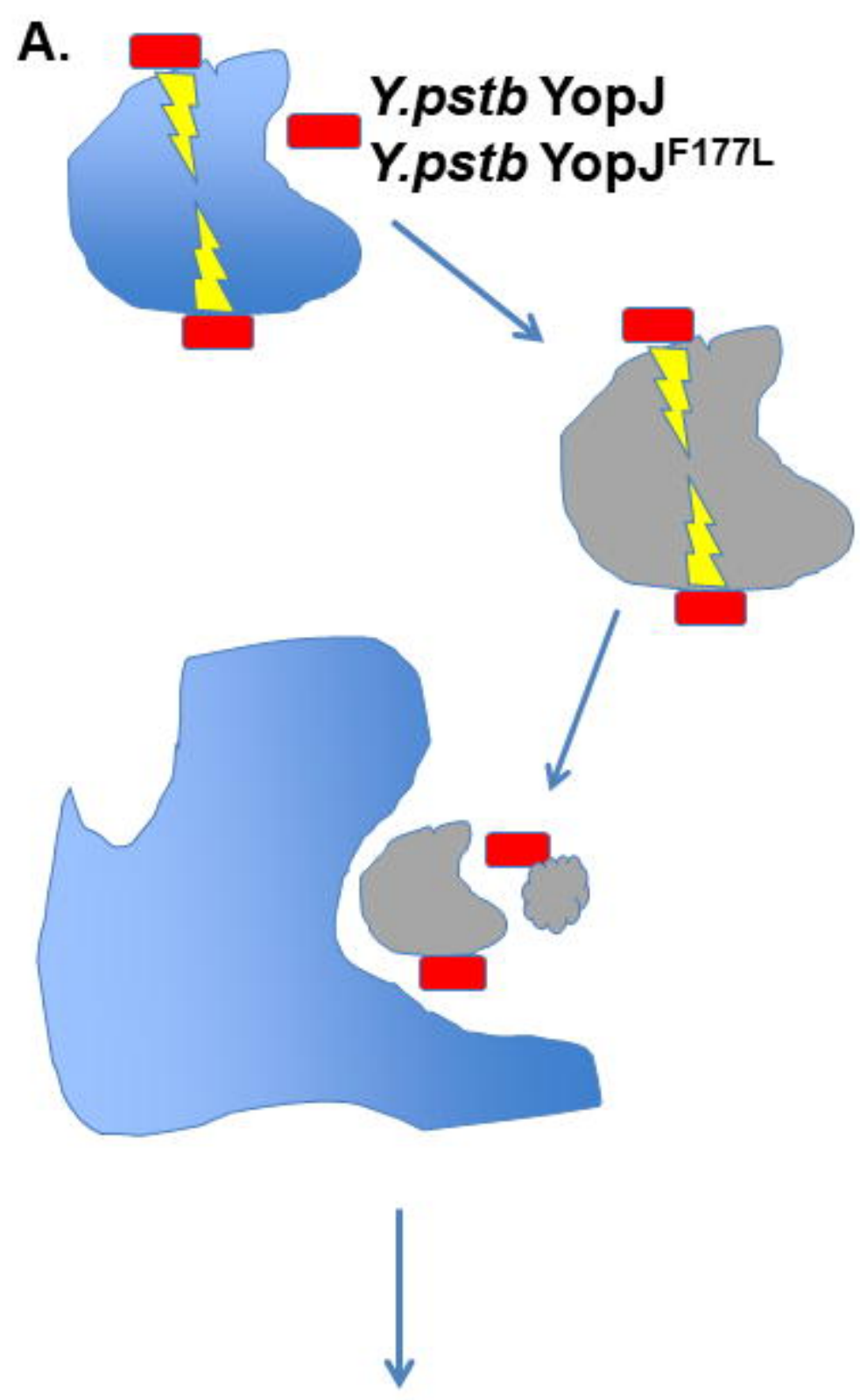

Pathogen clearance
B.

Y.pstb YopJY.pstb YopJ ${ }^{\mathrm{C172A}}$

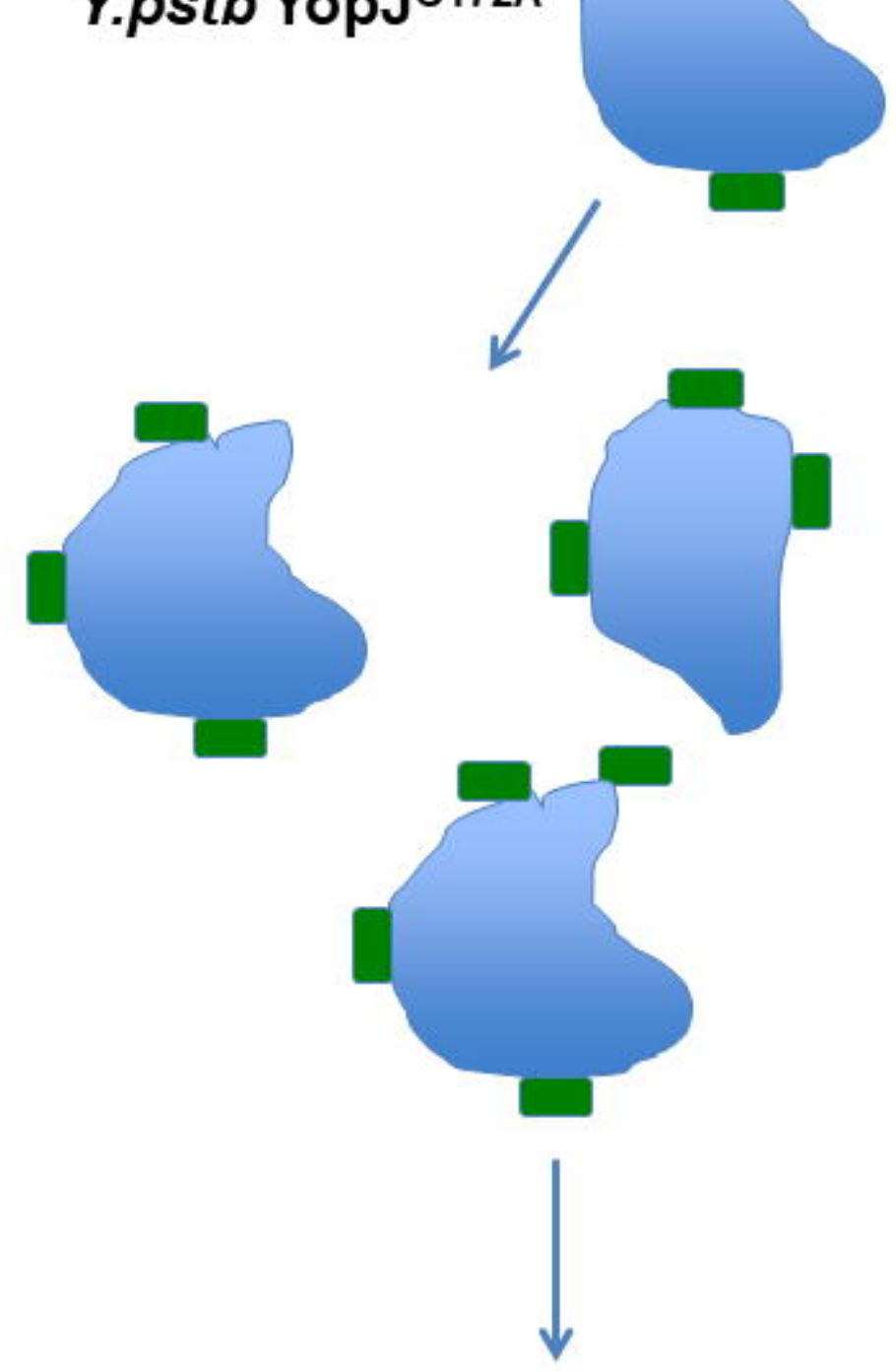

Persistence and death 